\title{
Polarimetric Relations for Snow Estimation-Radar Verification
}

\author{
Petar Bukovčić \\ Cooperative Institute for Mesoscale Meteorological Studies, University of Oklahoma, and \\ NOAA/OAR National Severe Storms Laboratory, Norman, Oklahoma \\ ALEXANDER RYZHKOV \\ Cooperative Institute for Mesoscale Meteorological Studies, University of Oklahoma, Norman, Oklahoma \\ DUSAN ZRNIĆ \\ National Severe Storms Laboratory, and School of Meteorology, and School of Electrical and Computer Engineering, \\ University of Oklahoma, Norman, Oklahoma \\ (Manuscript received 5 June 2019, in final form 25 February 2020)

\begin{abstract}
In a 2018 paper by Bukovčić et al., polarimetric bivariate power-law relations for estimating snowfall rate $S$ and ice water content (IWC), $S\left(K_{\mathrm{DP}}, Z\right)=\gamma K_{\mathrm{DP}}^{\alpha} Z^{\beta}$ and $\operatorname{IWC}\left(K_{\mathrm{DP}}, Z\right)=\gamma_{2} K_{\mathrm{DP}}^{\alpha_{2}} Z^{\beta_{2}}$, were developed utilizing $2 \mathrm{D}$ video disdrometer snow measurements in Oklahoma. Herein, these disdrometer-based relations are generalized for the range of particle aspect ratios from 0.5 to 0.8 and the width of the canting angle distribution from $0^{\circ}$ to $40^{\circ}$ and are validated via analytical/theoretical derivations and simulations. In addition, a novel $S\left(K_{\mathrm{DP}}, Z_{\mathrm{dr}}\right)$ polarimetric relation utilizing the ratio between specific differential phase $K_{\mathrm{DP}}$ and differential reflectivity $Z_{\mathrm{dr}}, K_{\mathrm{DP}} /\left(1-Z_{\mathrm{dr}}^{-1}\right)$, is derived. Both $K_{\mathrm{DP}}$ and $\left(1-Z_{\mathrm{dr}}^{-1}\right)$ are proportionally affected by the ice particles' aspect ratio and width of the canting angle distribution; therefore, the variables' ratio tends to be almost invariant to the changes in these parameters. The $S\left(K_{\mathrm{DP}}, Z\right)$ and $S\left(K_{\mathrm{DP}}, Z_{\mathrm{dr}}\right)$ relations are applied to the polarimetric S-band WSR-88D data obtained from three geographical locations in Virginia, Oklahoma, and Colorado, and their performance is compared with estimations from the standard $S(Z)$ relations and ground snow measurements. The polarimetric estimates of snow accumulations from the three cases exhibit smaller bias in comparison with the $S(Z)$, indicating good potential for more reliable radar snow measurements.
\end{abstract}

\section{Introduction}

Variability in ice crystal habits, shape, orientation, density, ice/water content, and snow size distributions (SSDs) introduces large uncertainty in snow measurements. A multitude of power-law relations between the equivalent radar reflectivity $Z$ and snow water equivalent rate $S, S(Z)$, have been developed for snow estimation (e.g., Gunn and Marshall 1958; Sekhon and Srivastava 1970; Fujiyoshi et al. 1990; Matrosov 2007, 2009; Szyrmer and Zawadzki 2010; Zhang et al. 2011; Heymsfield et al. 2016). A large number of these relations imply that $Z$ is proportional to $S^{2}$. The spread in the snow estimates among the $S(Z)$ relations is roughly an order of magnitude because $S(Z)$ s are prone to the variability of the size

Corresponding author: Petar Bukovčić, petar.bukovcic@ou.edu distributions of snow and its density. The National Weather Service (NWS) currently uses several standard $S(Z)$ relations for radar quantitative precipitation estimation (QPE) of snow (see Table 1 in Bukovčić et al. 2018), but it has not capitalized on the emergence of dual-polarization capabilities for snow QPE.

Numerous studies are conducted about the ice water content (IWC), an equally important microphysical parameter that quantifies the mass of cloud ice per unit volume of air. The majority of these studies utilize reflectivity factor $Z$ in a power-law form to estimate IWC (Sekhon and Srivastava 1970; Heymsfield 1977, 2005, 2016; Sassen 1987; Atlas et al. 1995; Liu and Illingworth 2000; Hogan et al. 2006; Delanoë et al. 2014; Protat et al. 2016). A common feature among the $\operatorname{IWC}(Z)$ relations is large variability in space and time (Ryzhkov et al. 1998). While the NWS interest is primarily in QPE 
of snow, the modeling community is more interested in IWC because the adequate representation in numerical weather prediction models can significantly improve quantitative precipitation forecasts. A more detailed review of the $S(Z)$ and $\operatorname{IWC}(Z)$ relations is given in Bukovčić et al. (2018).

The advent of dual polarization opens new possibilities to classify snow habits and reduce the uncertainty in snow quantification, but the efforts toward this end have been limited. In the last 25 years, only a few studies have explored polarimetric methods, mostly with regard to IWC estimation. Vivekanandan et al. (1994) and Lu et al. (2015) used specific differential phase $K_{\text {DP }}$ $\left({ }^{\circ} \mathrm{km}^{-1}\right)$ for this purpose. Aydin and Tang (1995) investigated clouds composed of pristine ice crystals, assuming that the density of crystals is equal to the density of solid ice and combined $K_{\mathrm{DP}}$ with differential reflectivity $Z_{\mathrm{DR}}$ for IWC estimation. Ryzhkov et al. (1998, 2018) used a combination of $K_{\mathrm{DP}}$ and differential reflectivity $Z_{\mathrm{DR}}$ or $K_{\mathrm{DP}}$ alone for IWC estimation of pristine or lightly to moderately aggregated ice crystals. Nguyen et al. $(2017,2019)$ used instrumented aircraft to derive an empirical relation from the simultaneous measurements of $K_{\mathrm{DP}}$ and $Z_{\mathrm{DR}}$ with a side-looking airborne X-band radar and in situ measurements of IWC. Recently, Bukovčić (2017) and Bukovčić et al. (2018) utilized a large dataset of 2D video disdrometer (2DVD) snow measurements in Oklahoma to derive polarimetric relations (at $\mathrm{S}$ band, applicable to $\mathrm{C}$ and $\mathrm{X}$ bands) for snow water equivalent rate and ice water content estimation. These bivariate power-law relations were derived from the 2DVD-measured snow size distributions utilizing $K_{\mathrm{DP}}$ and reflectivity at horizontal polarization $Z_{h}$ (herein $Z$ ). Capozzi et al. (2020) used similar approach as Bukovčić (2017) and Bukovčić et al. (2018) to derive polarimetric relations for snowfall-rate estimation at $\mathrm{X}$ band based on $K_{\mathrm{DP}}$ and $Z$, or $K_{\mathrm{DP}}$ alone. They tested the X-band relations for dry snow in the southern Apennine Mountains and compared these with the (wavelength scaled) relations from Bukovčić et al. (2018). The demonstration showed that the addition of $K_{\mathrm{DP}}$ enhances the accuracy of precipitation estimates with respect to the $Z$-based relations.

This paper extends the study of Bukovčić et al. (2018) by introducing generalized forms of the $S\left(K_{\mathrm{DP}}, Z\right)$ and $\operatorname{IWC}\left(K_{\mathrm{DP}}, Z\right)$ relations for dry aggregated snow. The generalized relations are derived by varying the range of aspect ratios $(b / a)$ from 0.5 to 0.8 and width of the canting angle distribution $\sigma$ from $0^{\circ}$ to $40^{\circ}$. In addition, we propose a novel polarimetric estimator of $S$ that uses a combination of $K_{\mathrm{DP}}$ and $Z_{\mathrm{dr}}, S\left(K_{\mathrm{DP}}, Z_{\mathrm{dr}}\right)$. The $S\left(K_{\mathrm{DP}}, Z_{\mathrm{dr}}\right)$ relation is derived via the theoretical approach utilized in Ryzhkov et al. (2018) and Ryzhkov and Zrnic (2019) to obtain the IWC $\left(K_{\mathrm{DP}}, Z_{\mathrm{dr}}\right)$ relation. Both algorithms for snowfall rate $S$ were tested using S-band WSR-88D polarimetric radar data for three snow events observed in Virginia, Oklahoma, and Colorado.

The paper is structured as follows: Theoretical aspects of polarimetric estimations of snow are discussed in section 2. The method of radar measurements is presented in section 3 , followed by the performance analysis of the suggested polarimetric algorithms for three snow events in section 4. Section 5 contains a discussion, followed by a summary of results at the end.

\section{Polarimetric relations for estimation of $S$ and IWC}

\section{a. Theoretical polarimetric relations for $S$ and IWC estimation}

Theoretical polarimetric relations for estimation of ice water content and snowfall rate at $\mathrm{S}$ band can be derived in the Rayleigh approximation assuming exponential size distribution (Gunn and Marshall 1958; Ohtake 1970; Sekhon and Srivastava 1970; Lo and Passarelli 1982; Braham 1990; Mitchell et al. 1990; Field 1999; Field and Heymsfield 2003; Matrosov and Heymsfield 2017):

$$
N(D)=N_{0 s} \exp \left(-\Lambda_{s} D\right)=N_{0 s} \exp \left(-\frac{4}{D_{m}} D\right),
$$

where $D_{m}$ is the mean volume diameter of ice particles. Power-law dependencies of snow density $\rho_{s}$ and terminal velocity $V_{t}$ on the snowflake equivolume diameter $D$ are

$$
\begin{aligned}
& \rho_{s}(D)=\alpha_{1} D^{\beta_{1}} \quad \text { and } \\
& V_{t}(D)=\tau_{1} D^{\delta_{1}}=d_{1} f\left(\rho_{a}\right) D^{\delta_{1}},
\end{aligned}
$$

where $\beta_{1}$ is close to -1 and $\tau_{1}$ is a function of an air density or atmospheric pressure, $f\left(\rho_{a}\right)=\left(p_{0} / p\right)^{0.5}$. Here, $p_{0}$ and $p$ are the atmospheric pressures (standard atmosphere) at the mean sea level (MSL; $\left.p_{0}=1013 \mathrm{hPa}\right)$ and at the measurement altitude above the MSL $(p)$. The ratio $\left(p_{0} / p\right)^{0.5}$ represents terminal velocity adjustment due to the air density change with the altitude referenced at the MSL (Brandes et al. 2008). Multiplier $d_{1}(\approx 0.9)$ and the exponent $\delta_{1}(\approx 0.15)$ are geometric means of the two empirical terminal velocities measured at $1750 \mathrm{~m}$ MSL in Colorado (Brandes et al. 2007). Herein, $d_{1}$ is adjusted to the MSL pressure $p_{0}=1013 \mathrm{hPa}$; hence $d_{1}=0.9\left(p_{1750} / p_{0}\right)^{0.5} \approx 0.81$ (where $p_{1750}=820 \mathrm{hPa}$ ).

The basic formulas for IWC, $S, Z$, and $K_{\mathrm{DP}}$ are (Ryzhkov and Zrnic 2019) 


$$
\begin{aligned}
\mathrm{IWC} & =\frac{\pi}{6} \times 10^{-3} \int_{0}^{D_{\max }} \rho_{s}(D) D^{3} N(D) d D \\
S & =0.6 \times 10^{-3} \pi \int_{0}^{D_{\max }} \frac{\rho_{s}(D)}{\rho_{w}} D^{3} V_{t}(D) N(D) d D \\
Z & =\frac{\left|K_{i}\right|^{2}}{\left|K_{w}\right|^{2}} \int_{0}^{D_{\max }} \frac{\rho_{s}^{2}(D)}{\rho_{i}^{2}} D^{6} N(D) d D, \quad \text { and } \\
K_{\mathrm{DP}} & =\frac{0.27 \pi F_{o} F_{s}}{\lambda \rho_{i}^{2}}\left(\frac{\varepsilon_{i}-1}{\varepsilon_{i}+2}\right)^{2} \int_{0}^{D_{\max }} \rho_{s}^{2}(D) D^{3} N(D) d D
\end{aligned}
$$

where $\rho_{w}, \rho_{i}$, and $\rho_{s}$ are the densities of water, solid ice, and snow, respectively; $\lambda$ is the radar wavelength; $K_{w}=\left(\varepsilon_{w}-1\right) /\left(\varepsilon_{w}+2\right) ; K_{i}=\left(\varepsilon_{i}-1\right) /\left(\varepsilon_{i}+2\right)$; and $\varepsilon_{w}$ and $\varepsilon_{i}$ are the dielectric constants of water and solid ice. The orientation factor $F_{o}=$ $(1 / 2) \exp \left(-2 \sigma^{2}\right)\left[1+\exp \left(-2 \sigma^{2}\right)\right]$ is a function of the width of the canting angle distribution $\sigma$ (in radians).
The shape factor $F_{s}=L_{b}-L_{a}$ is determined by the shape parameters $L_{a}$ and $L_{b}$ [see (18) in Bukovčić et al. 2018]. Using (1)-(7), one can arrive at the following $\operatorname{IWC}\left(K_{\mathrm{DP}}, Z\right)$ and $S\left(K_{\mathrm{DP}}, Z\right)$ theoretical relations (see the appendix):

$$
\operatorname{IWC}\left(K_{\mathrm{DP}}, Z\right)=c_{i} K_{\mathrm{DP}}^{\left(3+\beta_{1}\right) / 3} Z^{-\beta_{1} / 3},
$$

where

$$
c_{i}=\frac{2.95 \times 10^{-3} \times \Gamma\left(4+\beta_{1}\right)}{\alpha_{1}\left[\frac{F_{o} F_{s}}{\lambda} \times \Gamma\left(4+2 \beta_{1}\right)\right]^{\left(3+\beta_{1}\right) / 3}\left[1.26 \times \Gamma\left(7+2 \beta_{1}\right)\right]^{-\beta_{1} / 3}},
$$

and

$$
S\left(K_{\mathrm{DP}}, Z\right)=c_{s} K_{\mathrm{DP}}^{\left(3+\beta_{1}-\delta_{1}\right) / 3} Z^{\left(\delta_{1}-\beta_{1}\right) / 3},
$$

with

$$
c_{s}=\frac{10.61 \times 10^{-3} \times d_{1} f\left(\rho_{a}\right) \times \Gamma\left(4+\beta_{1}+\delta_{1}\right)}{\alpha_{1}\left[\frac{F_{o} F_{s}}{\lambda} \times \Gamma\left(4+2 \beta_{1}\right)\right]^{\left(3+\beta_{1}-\delta_{1}\right) / 3}\left[1.26 \times \Gamma\left(7+2 \beta_{1}\right)\right]^{\left(\delta_{1}-\beta_{1}\right) / 3}},
$$

where $\Gamma$ is complete gamma function. These relations are parameterized by the factors $F_{o}$ and $F_{s}$, which are unknown a priori. The theoretical expressions for $\operatorname{IWC}\left(K_{\mathrm{DP}}, Z\right)$ and $S\left(K_{\mathrm{DP}}, Z\right),(8)$ and (10), assuming $\sigma=0^{\circ}, b / a=0.65, \alpha_{1}=0.178, \beta_{1} \approx-1$, $f\left(\rho_{a}\right)=\left(p_{0} / p_{350}\right)^{0.5}$ (the Oklahoma measurements altitude is $\sim 350 \mathrm{~m}$; hence $\left.p_{350}=972 \mathrm{hPa}\right), d_{1} \approx 0.81$, $\delta_{1} \approx 0.15$, and radar wavelength $\lambda=110.8 \mathrm{~mm}$ ( $\mathrm{S}$ band), are

$$
\begin{aligned}
S\left(K_{\mathrm{DP}}, Z\right) & =1.62 K_{\mathrm{DP}}^{0.62} Z^{0.38} \text { and } \\
\operatorname{IWC}\left(K_{\mathrm{DP}}, Z\right) & =0.77 K_{\mathrm{DP}}^{0.67} Z^{0.33} .
\end{aligned}
$$

Such relations are very close to the empirical Oklahoma 2DVD-based relations

$$
\begin{aligned}
S\left(K_{\mathrm{DP}}, Z\right) & =1.48 K_{\mathrm{DP}}^{0.61} Z^{0.33} \text { and } \\
\operatorname{IWC}\left(K_{\mathrm{DP}}, Z\right) & =0.71 K_{\mathrm{DP}}^{0.66} Z^{0.28}
\end{aligned}
$$

from Bukovčić et al. (2018).

The $\operatorname{IWC}\left(K_{\mathrm{DP}}, Z\right)$ and $S\left(K_{\mathrm{DP}}, Z\right)$ estimators depend on the orientation and shape of the ice particles through the factors $F_{o}$ and $F_{s}$ in (9) and (11). Ryzhkov et al. (2018) and Ryzhkov and Zrnic (2019) suggest using a combination of $K_{\mathrm{DP}}$ and $Z_{\mathrm{dr}}$ instead of the combined use of $K_{\mathrm{DP}}$ and $Z$ to avoid the sensitivity of the IWC and $S$ estimates to the particle shapes and orientations. For example, it was shown that the estimate of IWC

$$
\operatorname{IWC}\left(K_{\mathrm{DP}}, Z_{\mathrm{dr}}\right)=3.96 \times 10^{-3} \frac{K_{\mathrm{DP}} \lambda}{1-Z_{\mathrm{dr}}^{-1}}
$$

is practically immune to the variability of shapes and orientations (Ryzhkov et al. 2018). In (12), $Z_{\mathrm{dr}}$ is the differential reflectivity expressed in linear scale $\left[Z_{\mathrm{dr}}=10^{0.1 Z_{\mathrm{DR}}(\mathrm{dB})}\right]$. It follows from the studies of Nguyen et al. $(2017,2019)$ that the theoretical relation (12) is very close to the empirical one derived from the simultaneous measurements of $K_{\mathrm{DP}}$ and $Z_{\mathrm{DR}}$ with a side-looking airborne $\mathrm{X}$-band radar and in situ measurements of IWC on board the Convair-580 aircraft during the High Altitude Ice Crystals-High Ice Water Content (HAIC-HIWC) field campaign.

Snow rate $S$ can be obtained from the combination of IWC and mean volume diameter $D_{m}$ as (see the appendix)

$$
S=c_{i i} \mathrm{IWC} \times D_{m}^{\delta_{1}}
$$

with 


$$
\begin{aligned}
c_{i i} & =\frac{3.6}{4^{\delta_{1}}} d_{1} f\left(\rho_{a}\right) \frac{\Gamma\left(4+\beta_{1}+\delta_{1}\right)}{\Gamma\left(4+\beta_{1}\right)}, \text { or } \\
S & =c_{i s} \frac{K_{\mathrm{DP}} \lambda}{1-Z_{\mathrm{dr}}^{-1}} D_{m}^{\delta_{1}}
\end{aligned}
$$

where

$$
c_{i s}=\frac{14.26 \times 10^{-3}}{4^{\delta_{1}}} d_{1} f\left(\rho_{a}\right) \frac{\Gamma\left(4+\beta_{1}+\delta_{1}\right)}{\Gamma\left(4+\beta_{1}\right)},
$$

which displays the connection between the IWC and $S$ through the change in snow terminal velocity via the term $d_{1} f\left(\rho_{a}\right) D_{m}^{\delta_{1}}$ (see the appendix). The $S\left(K_{\mathrm{DP}}, Z_{\mathrm{dr}}\right)$ estimate is prone to the differential reflectivity $Z_{\mathrm{DR}}$ miscalibration. The $S\left(K_{\mathrm{DP}}, Z_{\mathrm{dr}}\right)$ estimate may become unreliable in the presence of a $Z_{\mathrm{DR}}$ bias and at low values of $Z_{\mathrm{DR}}\left(Z_{\mathrm{DR}}<0.3-0.4 \mathrm{~dB}\right)$ and $K_{\mathrm{DP}}\left(K_{\mathrm{DP}}<\right.$ $\left.0.01^{\circ} \mathrm{km}^{-1}\right)$. The results of simulations using gamma size distributions indicate some sensitivity of $S\left(K_{\mathrm{DP}}\right.$, $\left.Z_{\mathrm{dr}}\right)$ to the shape parameter $\mu$, but the impact of the $\mu$ variability is relatively small. It is within $25 \%$ if $\mu$ varies between -1 and 2 .

The same assumptions as in the section describing the theoretical $\operatorname{IWC}\left(K_{\mathrm{DP}}, Z\right)$ and $S\left(K_{\mathrm{DP}}, Z\right)$ relations with regard to $\alpha_{1}, \beta_{1}, d_{1}, \delta_{1}, f\left(\rho_{a}\right)$, and $\lambda$, when applied in (15) and (16), yield the following $S\left(K_{\mathrm{DP}}, Z_{\mathrm{dr}}\right)$ relation

$$
S\left(K_{\mathrm{DP}}, Z_{\mathrm{dr}}\right)=10.8 \times 10^{-3}\left(\frac{p_{0}}{p}\right)^{0.5} \frac{K_{\mathrm{DP}}^{\lambda}}{1-Z_{\mathrm{dr}}^{-1}} D_{m}^{0.15}
$$

where

$$
D_{m}=-0.1+2\left(\frac{Z_{\mathrm{dp}}}{K_{\mathrm{DP}} \lambda}\right)^{1 / 2},
$$

and $Z_{\mathrm{dp}}=Z_{h}-Z_{v}$ is the reflectivity difference assuming that the reflectivity factors at orthogonal polarizations are in linear scale. In (17) and (18), $S$ is expressed in millimeters per hour, $K_{\mathrm{DP}}$ is in degrees per kilomter, $\lambda$ is in millimeters, $D_{m}$ is in millimeters, and $Z_{\mathrm{dp}}$ is in $\mathrm{mm}^{6} \mathrm{~m}^{-3}$.

\section{b. Empirical polarimetric relations for $S$ and IWC estimation}

The $S\left(K_{\mathrm{DP}}, Z\right)$ and $\operatorname{IWC}\left(K_{\mathrm{DP}}, Z\right)$ relations presented in Bukovčić et al. (2018) were obtained from disdrometer measurements assuming $\sigma=0^{\circ}$ and $b / a=0.65$. Here we introduce a generalized relation for $S\left(K_{\mathrm{DP}}, Z\right)$ derived from the same Oklahoma 2DVD dataset, valid for the entire range of $\sigma\left(0^{\circ}-40^{\circ}\right)$ and $b / a(0.5-0.8)$ for aggregated snow and possibly across different geographical regions:
$S\left(K_{\mathrm{DP}}, Z\right)=\frac{27.9 \times 10^{-3}}{\left(F_{o} F_{s}\right)^{0.615}}\left(\frac{p_{0}}{p}\right)^{0.5}\left(K_{\mathrm{DP}} \lambda\right)^{0.615} Z^{0.33}$

The equation in (19) comes down to

$$
S\left(K_{\mathrm{DP}}, Z\right)=1.48 K_{\mathrm{DP}}^{0.615} Z^{0.33}
$$

of Bukovčić et al. (2018) for $\sim 350 \mathrm{~m}$ MSL altitude (Oklahoma measurements; $p=972 \mathrm{hPa}$ ), $\sigma=0^{\circ}, b / a=$ 0.65 , and $\lambda=110.8 \mathrm{~mm}$. The adjustment factor $\left(p_{0} / p\right)^{0.5}$ accounting for the pressure dependence of the particle terminal velocity (Brandes et al. 2008) almost entirely contributes to the difference between the relations' multipliers to $\sim 2700$-m differential altitude between the Oklahoma and Colorado measurements in Bukovčić et al. (2018).

The generalized relation for IWC, also derived from the 2DVD Oklahoma dataset, has a form

$$
\operatorname{IWC}\left(K_{\mathrm{DP}}, Z\right)=\frac{10.2 \times 10^{-3}}{\left(F_{o} F_{s}\right)^{0.66}}\left(K_{\mathrm{DP}} \lambda\right)^{0.66} Z^{0.28} .
$$

The equation in (20) produces

$$
\operatorname{IWC}\left(K_{\mathrm{DP}}, Z\right)=0.71 K_{\mathrm{DP}}^{0.66} Z^{0.28}
$$

of Bukovčić et al. (2018) for $\sigma=0^{\circ}, b / a=0.65$, and $\lambda=$ $110.8 \mathrm{~mm}$. Both polarimetric relations (19) and (20) are obtained by varying $\sigma$ from $0^{\circ}$ to $40^{\circ}$ and $b / a$ from 0.5 to 0.8 and computing the regression coefficients from corresponding $K_{\mathrm{DP}}$ and $Z$.

For snowfall estimation in this study, we assume $b / a=$ 0.6 [the middle of the range from 0.5 to 0.7 found in the aggregated snow by Korolev and Isaac (2003)] and hypothesize that $\sigma$ linearly increases from the dendritic growth layer (DGL) toward the ground in the process of aggregation. This assumption is supported by the findings in the previous studies (Matrosov et al. 2005; Melnikov and Straka 2013) where the parameter $\sigma$ is close to $10^{\circ}$ within the DGL $\left(-20^{\circ}<T_{\text {air }}<-10^{\circ} \mathrm{C}\right)$. Below the DGL at higher temperatures, where the process of aggregation intensifies, $\sigma$ increases up to $40^{\circ}$ (Hendry et al. 1987).

\section{c. Sensitivity of empirical polarimetric relations for $S$ and IWC estimation to $\sigma$ and $b / a$}

In Bukovčić et al. (2018), polarimetric relations for snow water equivalent rate and ice water content estimation are derived from 16 snowstorms in Oklahoma utilizing the 2DVD measurements. The family of relations, in a form of the bivariate power laws $S\left(K_{\mathrm{DP}}, Z\right)=\gamma K_{\mathrm{DP}}^{\alpha} Z^{\beta}$ and $\operatorname{IWC}\left(K_{\mathrm{DP}}, Z\right)=\gamma_{2} K_{\mathrm{DP}}^{\alpha_{2}} Z^{\beta_{2}}$, are derived for dry aggregated snow. The biggest uncertainty 
a)

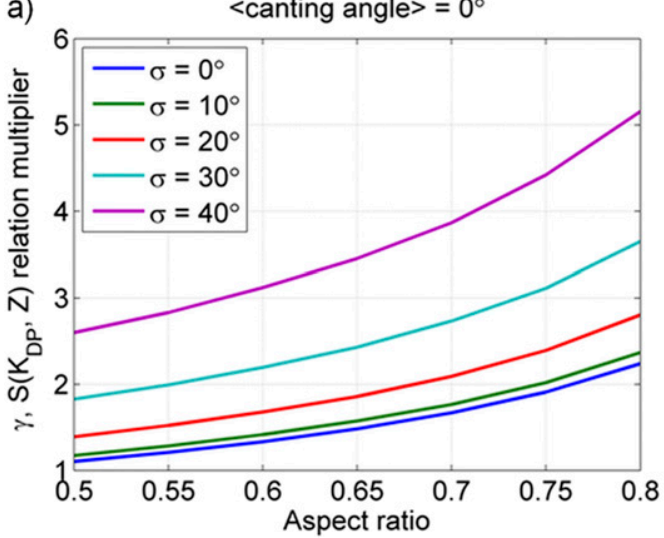

b)

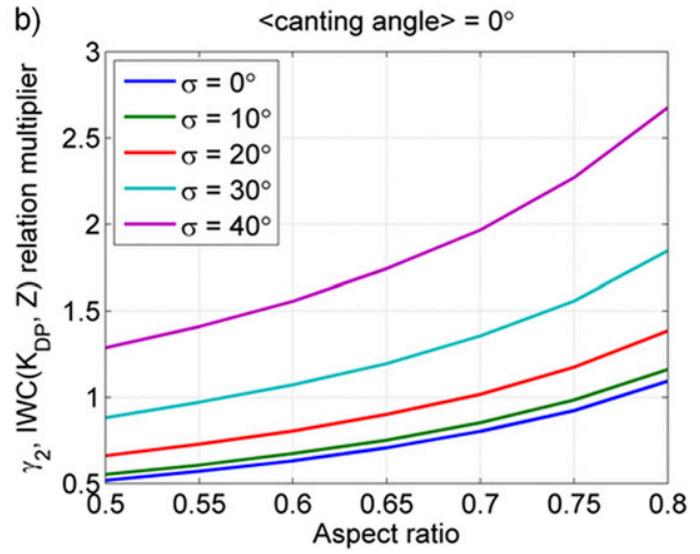

FIG. 1. The dependence of the (a) $S\left(K_{\mathrm{DP}}, Z\right)$ and (b) $\operatorname{IWC}\left(K_{\mathrm{DP}}, Z\right)$ relations' multipliers $\gamma$ and $\gamma_{2}$, respectively, on $\sigma$ and $b / a$, computed from Oklahoma 2DVD measurements for zero mean canting angle ( $\langle$ canting angle $\left.\rangle=0^{\circ}\right)$.

in a multiplier $\gamma$ (or $\gamma_{2}$ ) and exponents $\alpha$ and $\beta$ (or $\alpha_{2}$ and $\beta_{2}$ ) comes from the variability of $\sigma$ and $b / a$ whereas the change in the snow density is partially accounted for by the (density) adjustment through the ratio of squares of measured and prescribed empirical velocities [see (7) in Bukovčić et al. 2018].

Bukovčić (2017) demonstrated that simultaneous increase of $\sigma$ and $b / a$ affects very little the $K_{\mathrm{DP}}$ exponents $\alpha$ and $\alpha_{2}$ in the $S\left(K_{\mathrm{DP}}, Z\right)$ and $\operatorname{IWC}\left(K_{\mathrm{DP}}, Z\right)$ relations. The largest change in $\alpha\left(\alpha_{2}\right)$ is $0.3 \%(0.6 \%)$ for $\sigma=40^{\circ}$ and increase in $b / a$ from 0.5 to 0.8 . Similarly, the largest change in $Z$ exponent $\beta\left(\beta_{2}\right)$ is $0.4 \%(0.5 \%)$ for $\sigma=40^{\circ}$ and increase in $b / a$ from 0.5 to 0.8 , which implies that $\alpha$, $\alpha_{2}, \beta$, and $\beta_{2}$ can be regarded as invariant to changes in $\sigma$ and $b / a$. The situation is dramatically different regarding the $S\left(K_{\mathrm{DP}}, Z\right)$ and $\operatorname{IWC}\left(K_{\mathrm{DP}}, Z\right)$ relations' multipliers $\gamma$ and $\gamma_{2}$; their dependence on $\sigma$ and $b / a$ is presented in Figs. 1a and 1b. The multipliers of $S\left(K_{\mathrm{DP}}, Z\right)$ and $\operatorname{IWC}\left(K_{\mathrm{DP}}, Z\right)$ relations can increase by a factor of 2 and 2.1 for constant $\sigma$ and $b / a$ varying between 0.5 and 0.8 . If $\sigma$ and $b / a$ simultaneously increase from $0^{\circ}$ to $40^{\circ}$ and 0.5 to 0.7 (the latter values of $b / a$ are realistic for aggregated snow), then the increase in $\gamma$ and $\gamma_{2}$ are up to $\sim 3.5$ and 3.8 times, which makes a significant difference in the $S\left(K_{\mathrm{DP}}, Z\right)$ and $\operatorname{IWC}\left(K_{\mathrm{DP}}, Z\right)$ estimates (Bukovčić 2017). Note that for specific pairs of $\sigma$ and $b / a$ values, the multiplier of the $S\left(K_{\mathrm{DP}}, Z\right)$ relation is practically the same (Fig. 1a). For example, if the pair of values $(\sigma, b / a)$ is equal to $\left(0^{\circ}, 0.65\right)$, it produces the same $S\left(K_{\mathrm{DP}}, Z\right)$ relation as for $\left(13.5^{\circ}, 0.6\right)$ or $\left(18.75^{\circ}, 0.55\right)$ [and similarily for $\operatorname{IWC}\left(K_{\mathrm{DP}}, Z\right)$ ].

\section{Radar data processing}

Polarimetric radar measurements contain a plethora of information regarding hydrometeor characteristics, but not all measurements appear equally useful in their original format. For example, specific differential phase $K_{\mathrm{DP}}$ can be very noisy in snow, particularly at longer radar wavelengths (e.g., at $\mathrm{S}$ band). At $\mathrm{S}$ band, the values of $K_{\mathrm{DP}}$ are very small for the irregular-shape or aggregated snow (typically smaller than $0.05^{\circ} \mathrm{km}^{-1}$, with maxima up to $0.3^{\circ}-0.4^{\circ} \mathrm{km}^{-1}$ ). However, there are several big advantages that make $K_{\mathrm{DP}}$ very attractive: it is not biased by attenuation, system noise, or radar miscalibration, and is proportional to a lower-order moment of snow size distribution compared to radar reflectivity. With the emergence of new radar data displaying/processing techniques, such as quasi-vertical profiles (QVPs; Ryzhkov et al. 2016; Griffin et al. 2018), range-defined QVPs (RD-QVPs; Tobin and Kumjian 2017), enhanced vertical profiles (EVPs; Bukovčić et al. 2017), and columnar vertical profiles (CVPs; Murphy 2018), some of the challenges regarding the measurements/estimations of snow can be mitigated. The XVPs, where X stands for Q, RD-, E, and C, are obtained by azimuthal and/or spatial averaging of the radar measurements utilizing one or more PPI radar scans, and displayed as vertical profiles in a time versus height format. The $K_{\mathrm{DP}}$ is computed as a least squares fit of the radial slope of (averaged) differential phase $\Phi_{\mathrm{DP}}$ over two range intervals. For snow, the interval is $6 \mathrm{~km}$ (24 range gates) if $Z<40 \mathrm{~dB} Z$, whereas in the case of $Z \geq 40 \mathrm{~dB} Z$ the interval is $2 \mathrm{~km}$ ( 8 range gates). The relative calibration of $Z$ is not checked because the WSR-88Ds used in our study are calibrated to be within 1-dB error. The $Z_{\mathrm{DR}}$ calibration is performed by comparing the RD-QVP estimated $Z_{\mathrm{DR}}$ values in dry aggregated snow (relatively close to the ground) with the expected $Z_{\mathrm{DR}}$ values of $0.1-0.15 \mathrm{~dB}$.

The QVP method applied to $K_{\mathrm{DP}}$ (or any polarimetric variable) improves its statistical accuracy down to $0.01^{\circ} \mathrm{km}^{-1}$ due to azimuthal averaging over a $360^{\circ}$ circle, 
thereby decreasing the standard deviation of the $K_{\mathrm{DP}}$ estimate by a factor of $(360)^{0.5} \approx 19$. This is very important because the proposed method for snow measurements hinges on the accurate and reliable estimation of $K_{\mathrm{DP}}$. The accuracy is even greater if RD-QVPs are used because all available radar tilts are utilized instead of a single one in a standard QVP.

The CVP technique also uses substantial spatial averaging (similar to QVP), hence relatively high statistical accuracy of determination of the polarimetric variables is achieved. As opposed to QVP (or RD-QVP), the CVP is not a radar-centric product. It represents quasi-vertical profiles of radar variables at any location away from the radar. The CVP technique emerged as a generalization of the EVP (Bukovčić et al. 2017) product. In attempt to preserve a storm's homogeneity, the EVPs are constructed on a smaller spatial scale to preserve the localized nature of the processes. Thus, 3 radials by 5 range data points are used for averaging, where these moving average values extracted over the $5 \mathrm{~km}$ radial slanted length of all available elevations are mapped to the vertical. Subsequently, the updated version of the EVP-now rebranded as CVP-is constructed with typical spatial resolution of $20 \mathrm{~km}$ in range by $20^{\circ}$ in azimuth and additional smoothing (Cressman scheme) in the vertical. The location of the CVP (or EVP) column can be changed during the observations. For example, Murphy (2018) demonstrated that CVPs can be used to follow the aircraft along its flight path, and compared the microphysical retrievals of IWC from the WSR-88D polarimetric radar with the in situ (aircraft) measurements. For more details about the CVP the reader is referred to Murphy (2018).

These novel QVP/CVP techniques inspire another look at the existing PPI method. If the averaging is performed on $\mathrm{X}$ radials by $\mathrm{Y}$ range data points it produces similar accuracy of $K_{\mathrm{DP}}$ as the QVP/CVP method if the $\mathrm{XY}$ product is close to 360 . For example, if the location is $\sim 70 \mathrm{~km}$ from the radar, a $10 \mathrm{~km} \times 10 \mathrm{~km}$ box has $\sim 320$ data points for averaging (e.g., sample spacing resolution of $\sim 1^{\circ}$ in azimuth and $0.25 \mathrm{~km}$ in range), which is comparable to $\sim 360$ from QVP. Unless the spatial scale of the process is much smaller than the prescribed box size, storm's inhomogeneity/variability will have a minor impact on the accuracy of the radar estimates. The original PPI data are obtained from volume scans updated roughly every 5$6 \mathrm{~min}$, with $0.25-\mathrm{km}$ range spacing and $0.95^{\circ}-1^{\circ}$ beamwidth.

\section{Verification of polarimetric radar relations for snow with polarimetric radar data and direct snow measurements at the surface}

In this section, three cases for validation of $S\left(K_{\mathrm{DP}}, Z\right)$ and $S\left(K_{\mathrm{DP}}, Z_{\mathrm{dr}}\right)$ relations are examined. The measurements are obtained in dry and mostly aggregated snow with one high $(\sim 46-47 \mathrm{~mm})$ and two medium $(\sim 12 \mathrm{~mm}$ and $\sim 23 \mathrm{~mm})$ total snow liquid-water equivalent (SWE) accumulations in three geographical locations: Virginia, Oklahoma, and Colorado. The RD-QVPs, CVPs, and PPIs (data recorded at low elevations from $0.5^{\circ}$ to $2.4^{\circ}$ ) are temporally smoothed $(\sim 20 \mathrm{~min})$ and utilized for verification. The ASOS precipitation gauges [Dulles International Airport (IAD) and Baltimore-Washington International Airport (BWI)] are used as ground reference measurements for Virginia, along with a heated tipping bucket for Colorado and 2DVD for the Oklahoma case. The disdrometer (2DVD) was additionally tuned with the total amount of snow water equivalent (per event) obtained from CoCoRaHS or Oklahoma Mesonet measurements to reduce the particle mismatching, as explained in Bukovčić et al. (2018).

\section{a. 23 January 2016 East Coast blizzard, Virginia}

The first snowstorm in the analysis, the 23 January 2016 East Coast blizzard, produced about $46.5 \mathrm{~mm}$ of SWE in $24 \mathrm{~h}$ at the two ASOS locations that are 74 and $3 \mathrm{~km}$ in distance and $71^{\circ}$ and $125^{\circ}$ in azimuth with respect to the KLWX WSR-88D (Sterling, Virginia). The storm, ranked fourth among the highest-impact snow events in the urban Northeast (https://www.ncdc.noaa.gov/snowand-ice/rsi/nesis), disrupted the day's activities and services from the Washington, D.C., area to New York, affecting a vast number of people. In several places, the storm produced blizzard conditions and accumulation totals exceeding previous records.

The KLWX PPIs $\left(1.45^{\circ}\right.$ elevation angle) of $Z, K_{\mathrm{DP}}$, $Z_{\mathrm{DR}}$, and $\rho_{\mathrm{hv}}$ (Fig. 2) reveal a complex storm morphology. Several snowbands/cells are most evident in $Z$ and $K_{\mathrm{DP}}$ fields within the widespread snow precipitation. Relatively high (for snow) $K_{\mathrm{DP}}$ values $\left(>0.15^{\circ} \mathrm{km}^{-1}\right)$ are not always collocated with high $Z$ values $(>30 \mathrm{~dB} Z)$ as seen at $\sim 70 \mathrm{~km}$ north-northeast from the radar. It is expected to find high $K_{\mathrm{DP}}$ values within the DGL (from $-10^{\circ}$ to $-20^{\circ} \mathrm{C}$ ) where $Z$ is relatively small (Kennedy and Rutledge 2011; Bechini et al. 2013). As aggregation strengthens, $Z$ increases with the highest values close to the ground. Oftentimes, if the temperatures are sufficiently low $\left(<-5^{\circ} \mathrm{C}\right)$, some enhanced $K_{\mathrm{DP}}$ values can be observed well below the DGL. $Z_{\mathrm{DR}}$ is generally noisy and close to zero within the bands of high $Z$ and increases where $Z$ decreases, whereas $\rho_{\mathrm{hv}}$ is mostly uniform and greater than 0.98 .

The analysis of snowfall-rate estimates and accumulations from standard $S(Z)$, and polarimetric $S\left(K_{\mathrm{DP}}, Z\right)$ and $S\left(K_{\mathrm{DP}}, Z_{\mathrm{dr}}\right)$ relations is focused on the averages from the rectangular area $(\sim 10 \mathrm{~km}$ by $10 \mathrm{~km}$ approximately $74 \mathrm{~km}$ east-northeast from the radar, with $\sim 320$ points used 

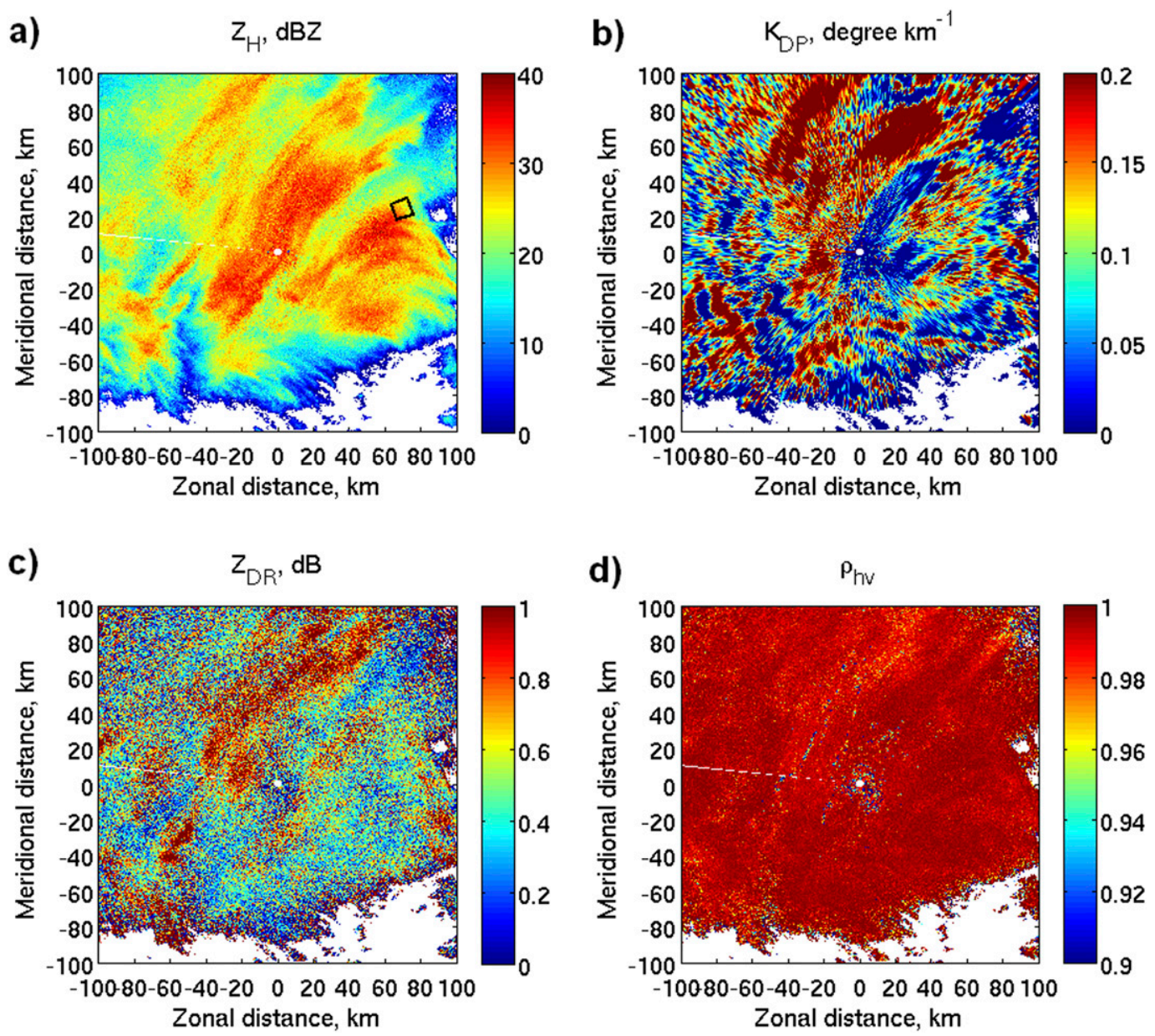

FIG. 2. PPIs of (a) $Z$, (b) $K_{\mathrm{DP}}$, (c) $Z_{\mathrm{DR}}$, and (d) $\rho_{\mathrm{hv}}$ for KLWX $1.45^{\circ}$ radar elevation angle at Sterling at 1034 UTC 23 Jan 2016. The black-outlined rectangle represents the $8^{\circ}$ in azimuth by 40 range points used for averaging, roughly $10 \mathrm{~km}$ by $10 \mathrm{~km}$; the height of the rectangle center is $\sim 2.3 \mathrm{~km}$ AGL, with the BWI ASOS location $(\sim 74 \mathrm{~km}$ east-northeast of KLWX) directly below. The IAD ASOS station is $\sim 3 \mathrm{~km}$ east-southeast from KLWX.

for averaging; Fig. 2a) centered above the ground BWI ASOS station used for verification. Instantaneous snowfall rates from the reference gauge, $S\left(K_{\mathrm{DP}}, Z\right)$, $S\left(K_{\mathrm{DP}}, Z_{\mathrm{dr}}\right)$, and $S(Z)$ are presented in Fig. 3a whereas their accumulations are in Fig. 3b. The radar estimates are obtained at $1.45^{\circ}$ elevation, which is about $2.3 \mathrm{~km}$ above the ground level. The times of the measurements aloft are adjusted for the average terminal velocity of snowflakes, $\sim 1 \mathrm{~m} \mathrm{~s}^{-1}$, to match the gauge measurements (about $38 \mathrm{~min}$ offset). During the periods of light snow, from 0000 to 0400 UTC and 1400 to 1800 UTC, the $S(Z)$ estimate is slightly better than the ones from $S\left(K_{\mathrm{DP}}, Z\right)$ and $S\left(K_{\mathrm{DP}}, Z_{\mathrm{dr}}\right)$, and it is the opposite within the moderate to high $\left(>2 \mathrm{~mm} \mathrm{~h}^{-1}\right)$ snowfall rates (Fig. 3a). The $S\left(K_{\mathrm{DP}}, Z\right)$ relation $\left(\sigma \approx 16^{\circ}\right.$ and $\left.b / a=0.6\right)$ usually captures the peaks in snowfall rate $\left(4.5-5.5 \mathrm{~mm} \mathrm{~h}^{-1}\right)$ very well, almost matching the gauge measurements $\left(4.5-5 \mathrm{~mm} \mathrm{~h}^{-1}\right)$. But during some periods (e.g., 0630, 2000 UTC), it overestimates $S$ up to $2.5 \mathrm{~mm} \mathrm{~h}^{-1}$. The $S\left(K_{\mathrm{DP}}, Z_{\mathrm{dr}}\right)$ peaks are slightly smaller but comparable with the gauge's. In contrast, $S(Z)$ does not produce the peaks over $3.2 \mathrm{~mm} \mathrm{~h}^{-1}$ during the entire storm. The accumulation from $S\left(K_{\mathrm{DP}}, Z\right)$ (red curve; Fig. $3 b$ ) is very close to the gauge measurements $(\sim 46.5 \mathrm{~mm}$; black dashed curve $)$. The $S\left(K_{\mathrm{DP}}, Z_{\mathrm{dr}}\right)$ estimate is not far behind $(\sim 42 \mathrm{~mm})$, but $S(Z)$ is significantly smaller $(\sim 29.5 \mathrm{~mm})$. The estimates from the $0.5^{\circ}$ radar elevation (not shown; $\sim 1.04 \mathrm{~km} \mathrm{AGL)} \mathrm{have} \mathrm{similar} \mathrm{tendencies;}$ $S\left(K_{\mathrm{DP}}, Z\right)$ peaks are somewhat higher $(7.85 \mathrm{~mm}$ at 0630 UTC, $\sigma \approx 22^{\circ}$ ) but the accumulation is close to the ground reference ( $48 \mathrm{~mm}$ vs $46.5 \mathrm{~mm})$. The $S\left(K_{\mathrm{DP}}, Z_{\mathrm{dr}}\right)$ accumulation is somewhat lower $(\sim 38.5 \mathrm{~mm})$, whereas $S(Z)$ is slightly higher $(\sim 32 \mathrm{~mm})$ with respect to their $1.45^{\circ}$ counterparts. This is expected as $S(Z)$ increases 

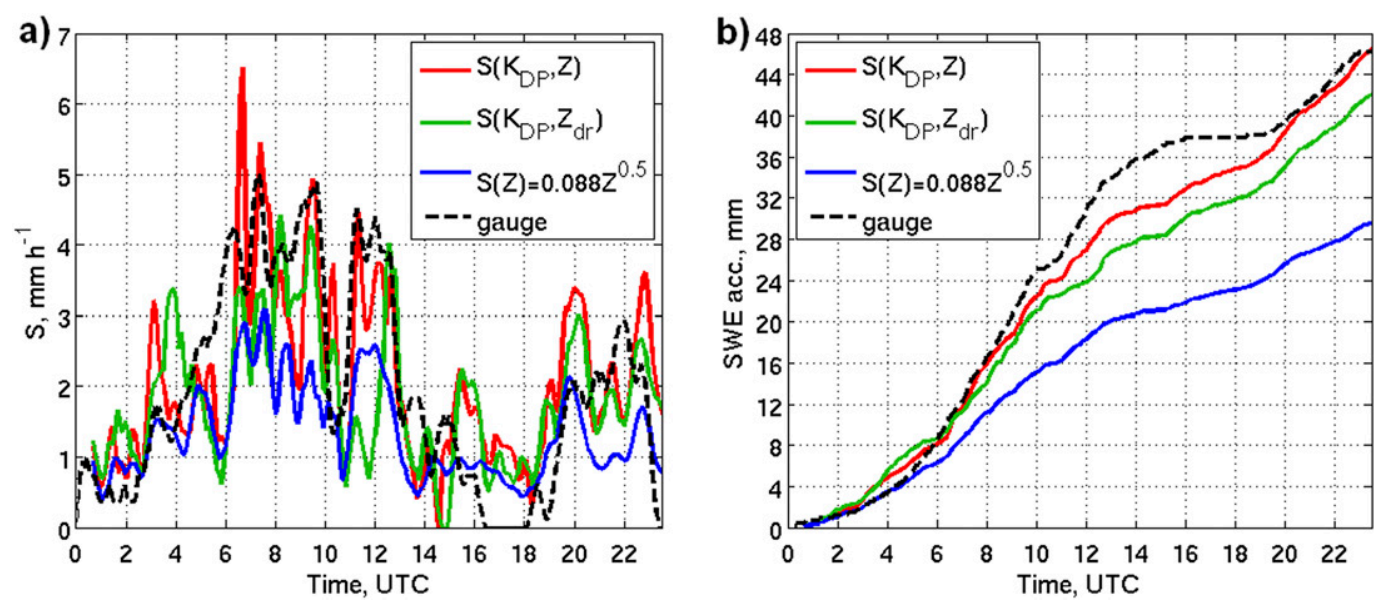

FIG. 3. For 23 Jan 2016, (a) instantaneous snowfall-rate $\left(\mathrm{mm} \mathrm{h}^{-1}\right)$ estimates from the BWI ASOS gauge (black dashed curve), $S\left(K_{\mathrm{DP}}, Z\right.$ ) (red curve), $S\left(K_{\mathrm{DP}}, Z_{\mathrm{dr}}\right)$ (green curve), and $S(Z)$ (blue curve); (b) respective SWE accumulations $(\mathrm{mm})$ from (a). Radar estimates are from $\sim 2.3 \mathrm{~km}$ AGL (1.45 elevation), obtained directly above the BWI ASOS location (black rectangle in Fig. $2 \mathrm{a}, \sim 74 \mathrm{~km}$ east-northeast from KLWX).

with decreasing elevation in the presence of aggregation. In contrast, $S\left(K_{\mathrm{DP}}, Z_{\mathrm{dr}}\right)$ should work the best in the temperature range from $-10^{\circ}$ to $-20^{\circ} \mathrm{C}$ within the DGL because of the enhancements in $K_{\mathrm{DP}}$ and $Z_{\mathrm{dr}}$ due to the rapid ice particles growth. Temperatures [obtained from Rapid Refresh (RAP) model at the BWI location, not shown] ranged from $-8^{\circ}$ to $-2^{\circ} \mathrm{C}$ and from $-9.5^{\circ}$ to $-4^{\circ} \mathrm{C}$ at the 2.3 and $1.04 \mathrm{~km}$ AGL heights, respectively, of the radar measurements. During the warmest period from 0300 to 1100 UTC the temperature varied from $-2^{\circ}$ to $-4^{\circ} \mathrm{C}$ and from $-4^{\circ}$ to $-8^{\circ} \mathrm{C}$ at 2.3 and $1.04 \mathrm{~km}$ AGL, respectively; hence the thermal profile was not optimal for the $S\left(K_{\mathrm{DP}}, Z_{\mathrm{dr}}\right)$ estimates.

The KLWX RD-QVPs (20-km radius, constructed from all available elevation angles) of $Z, K_{\mathrm{DP}}$, and $Z_{\mathrm{DR}}$ in a time-versus-height format, and profiles of SWE accumulations are presented in Fig. 4. The black dashed lines are isotherms from the RAP model, where the temperatures in the layer from $-10^{\circ}$ to $-20^{\circ} \mathrm{C}$ (often associated with DGL) are highlighted in magenta. There are some very informative features visible in RD-QVPs of $K_{\mathrm{DP}}$ and $Z_{\mathrm{DR}}$ within the DGL: there is a midlevel maxima in both variables (at about $-15^{\circ} \mathrm{C}$, especially in $Z_{\mathrm{DR}}$ ), with the $K_{\mathrm{DP}}$ enhancements extending well below the DGL in several periods (Figs. $4 \mathrm{~b}, \mathrm{c}$ ). The $K_{\mathrm{DP}}$ maxima are associated with the higher ice particle concentration. It is known that in DGL dendrites and plates experience the strongest growth (hence, dendritic growth layer) at the expense of water vapor. About $80 \%-90 \%$ of total precipitation is formed in this layer (Korolev et al. 2000 ), which, as seen from the RD-QVPs of $K_{\mathrm{DP}}$ and $Z_{\mathrm{DR}}$, has some pronounced signatures. This is mainly because the ice particles are nonspherical and have relatively high densities in the DGL. Below the DGL aggregation occurs, which decreases the density of the snow particles and redistributes the mass across the size spectrum, thereby contributing to an increase in $Z$ toward the ground. Close to the ground, both $K_{\mathrm{DP}}$ and $Z_{\mathrm{DR}}$ approach zero as the particles are more spherical, more chaotically oriented, and have generally lower density.

Another form of verification is presented through comparisons of the $S\left(K_{\mathrm{DP}}, Z\right)$ and $S\left(K_{\mathrm{DP}}, Z_{\mathrm{dr}}\right)$ relations' accumulations with collocated reference ground measurements at the IAD ASOS station next to the radar and standard $S(Z)$ WSR-88D relation (Fig. 4d). The vertical profiles of total snow accumulations are obtained as follows. The estimates of instantaneous snow rates $S$ are calculated from the profiles of $Z, Z_{\mathrm{DR}}$, and $K_{\mathrm{DP}}$ (Figs. 4a-c). Subsequently, the $S\left(K_{\mathrm{DP}}, Z\right), S\left(K_{\mathrm{DP}}, Z_{\mathrm{dr}}\right)$, and $S(Z)$ estimates are multiplied by the time interval between the radar scans, and the corresponding results are summed at the constant heights throughout the duration of the storm. The $S\left(K_{\mathrm{DP}}, Z\right)$ relation used for comparison provides the most realistic, and almost constant profile of SWE accumulation $(\sim 43 \mathrm{~mm}$, red curve) from $\sim 2$ to $\sim 0.5 \mathrm{~km}$ above the ground, nearly matching the ground reference gauge value (black cross; $\sim 46.5 \mathrm{~mm}$ ). Ideally, if the snow mass flux is conserved throughout this portion of the atmosphere, then no vertical dependence of snow accumulation is expected (below the DGL). The $S\left(K_{\mathrm{DP}}, Z_{\mathrm{dr}}\right)$ relation shows promise within the DGL ( $\sim 49 \mathrm{~mm}$; green curve), where lower temperatures and relatively high values of $K_{\mathrm{DP}}$ and $Z_{\mathrm{DR}}$ occur (in comparison to the values in aggregated snow), but the SWE estimates decrease substantially 
a)

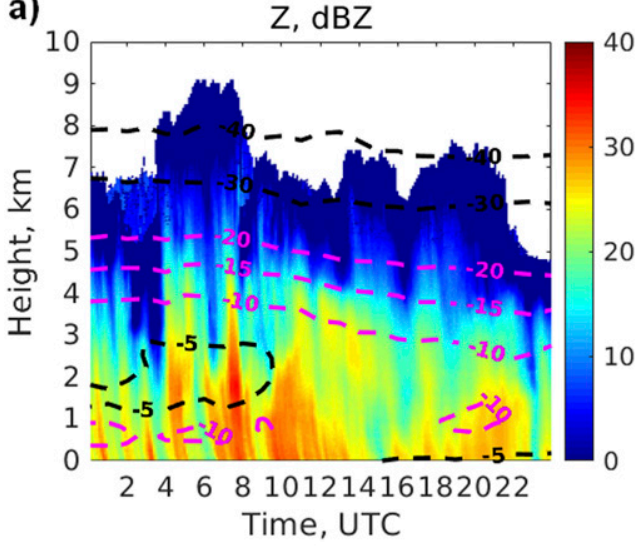

c)

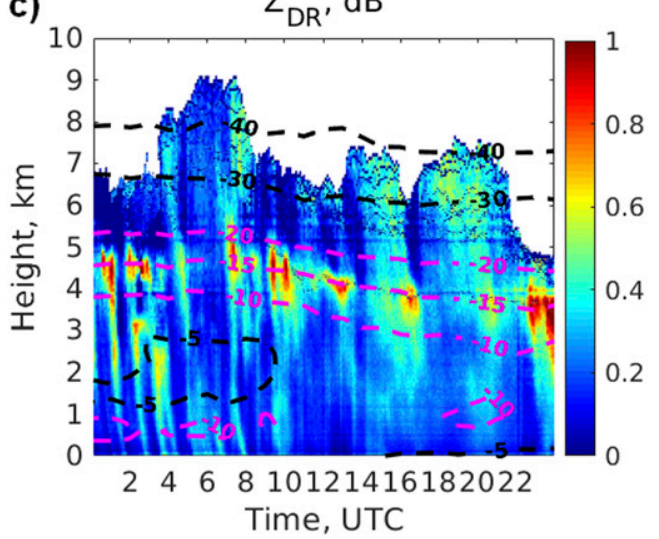

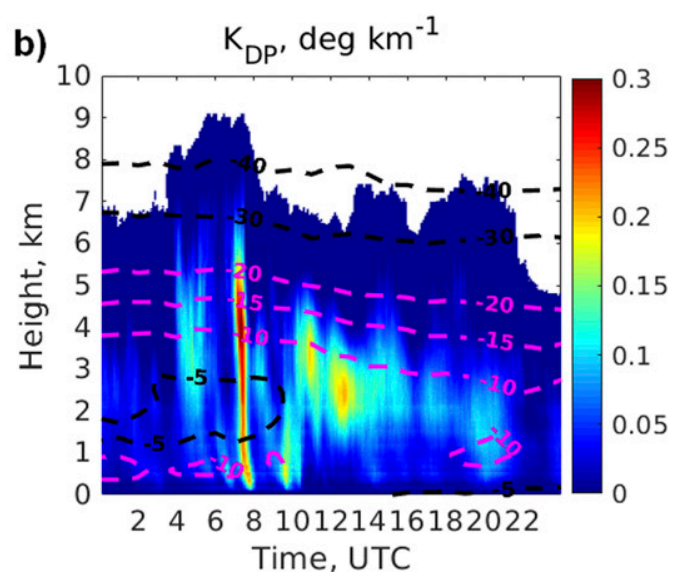

d)

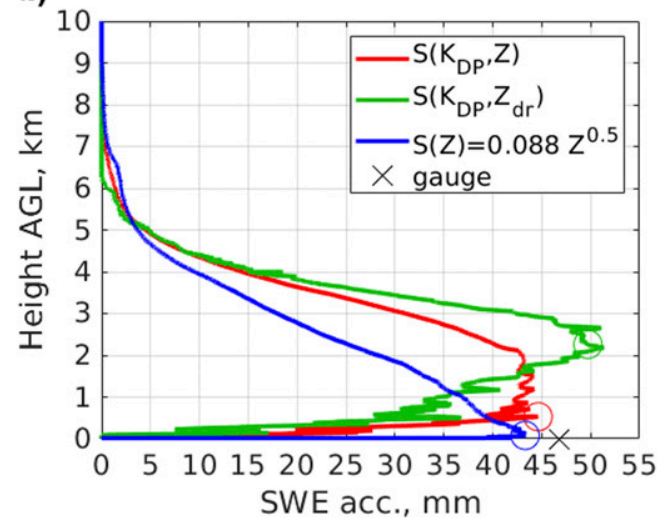

FIG. 4. For KLWX at Sterling on 23 Jan 2016, RD-QVPs of (a) $Z$, (b) $K_{\mathrm{DP}}$, and (c) $Z_{\mathrm{DR}}$; the black dashed lines are isotherms, where the layer from $-10^{\circ}$ to $-20^{\circ} \mathrm{C}$ that is highlighted in magenta represents DGL; (d) profiles of SWE accumulations from the IAD ASOS gauge (black cross, $\sim 3 \mathrm{~km}$ from radar), $S\left(K_{\mathrm{DP}}, Z\right)$ (red curve), $S\left(K_{\mathrm{DP}}, Z_{\mathrm{dr}}\right)$ (green curve), and $S(Z)$ (blue curve); the red, green, and blue open circles indicate from which heights the instantaneous estimates of $S$ are extracted (see Fig. 5, later).

toward the ground. The corresponding $S(Z)$ relation produces maximum $(\sim 43 \mathrm{~mm}$; blue curve) close to the ground due to snow aggregation.

Comparisons of instantaneous snowfall rates and their accumulations from various levels marked with colormatching circles in Fig. 4d are presented in Fig. 5. The levels are chosen so that the best estimates of $S$ from the corresponding relations could be compared side by side. The $S(Z)$ algorithm produces the best results next to the ground, $S\left(K_{\mathrm{DP}}, Z_{\mathrm{dr}}\right)$ is most accurate within the temperature range from $-20^{\circ}$ to $-10^{\circ} \mathrm{C}$ (DGL), and $S\left(K_{\mathrm{DP}}, Z\right)$ in the layer extending from the DGL to the proximity of the ground, depending on $K_{\mathrm{DP}}$ values $\left(K_{\mathrm{DP}}\right.$ needs to be large enough for the estimate to be made, $K_{\mathrm{DP}}>\sim 0.01^{\circ} \mathrm{km}^{-1}$ ). The $S\left(K_{\mathrm{DP}}, Z\right)$ estimator appropriately captures the variations as well as the peaks in $S$ with respect to the collocated gauge measurements most of the times. The $S\left(K_{\mathrm{DP}}, Z_{\mathrm{dr}}\right)$ output has more fluctuations and heavily overestimates $S$ from 1200 to 1600 UTC with respect to the $S\left(K_{\mathrm{DP}}, Z\right)$ estimate and gauge. This is somewhat expected due to the height difference between the estimates (ground vs $\sim 0.5 \mathrm{~km}$ vs $\sim 2.3 \mathrm{~km}$ ). It takes $\sim 38 \mathrm{~min}$ for snowflakes to fall on the ground from the $2.3 \mathrm{~km}$ altitude. The advection or sublimation at any level decreases the correlation between the ground measurements and the radar estimates aloft. Also, RD-QVP's radius is $20 \mathrm{~km}$, thus the cylinder of $40 \mathrm{~km}$ diameter is used for data averaging, in comparison to the one point gauge measurement at the ground level. Although snowfall rates smaller than $2.5 \mathrm{~mm} \mathrm{~h}^{-1}$ are captured relatively well, the $S(Z)$ relation's maxima are much smaller than the peaks in the ground measurements, even though the height of the $S(Z)$ estimate is $\sim 0.15 \mathrm{~km}$ AGL.

Accumulations from corresponding relations are presented in Fig. 5b. The shape of the $S\left(K_{\mathrm{DP}}, Z\right)$ accumulation curve (red) is the closest to the ground 

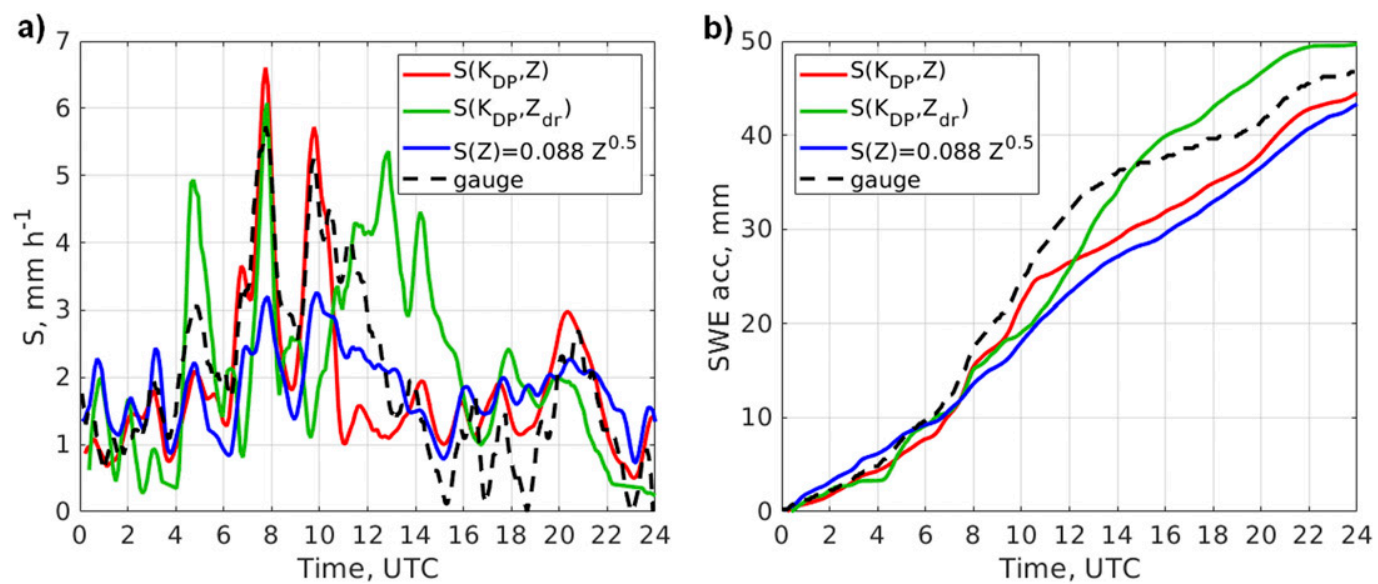

FIG. 5. For 23 Jan 2016 at Sterling, (a) instantaneous snowfall rates $\left(\mathrm{mm} \mathrm{h}^{-1}\right)$ from the IAD ASOS gauge (black dashed curve, ground), $S\left(K_{\mathrm{DP}}, Z\right)$ (red curve; $0.49 \mathrm{~km} \mathrm{AGL),} S\left(K_{\mathrm{DP}}, Z_{\mathrm{dr}}\right)$ (green curve; $2.26 \mathrm{~km} \mathrm{AGL),} \mathrm{and} S(Z)$ (blue curve; $0.15 \mathrm{~km}$ AGL) from the various heights marked as open circles in Fig. 4d; (b) respective SWE accumulations $(\mathrm{mm})$ from $(\mathrm{a})$.

measurement; the $S(Z)$ curve (blue) is slightly more consistent than the $S\left(K_{\mathrm{DP}}, Z_{\mathrm{dr}}\right)$ with the ground reference. Overall, all curves show good agreement. The RD-QVP $S(Z)$ estimate seems to be much closer to the reference (IAD) when compared with the PPI $S(Z)$ counterpart at BWI location $(\sim 74 \mathrm{~km}$ northeast of radar; Fig. 3d). If we look closer at Fig. 4d, however, the accumulation from $S(Z)$ at the altitude $\sim 2.3 \mathrm{~km}(\sim 1.04 \mathrm{~km})$ is $\sim 26 \mathrm{~mm}(\sim 36 \mathrm{~mm})$, which is consistent with the results from the PPIs at BWI location, showing the increase in the $S(Z)$ estimate toward the ground. This $S(Z)$ property has considerable impact on the measurements of aggregated snow: due to the increase in altitude of the radar beam, snowfall amounts farther away from the radar could be moderately underestimated. The $S\left(K_{\mathrm{DP}}, Z\right)$ estimates show that they are the least affected by the increasing (slanted) distance from the radar and provide the most robust results, but only if $\sigma$ and $b / a$ are known.

\section{b. 1 February 2011 case, Washington, Oklahoma}

The 1 February 2011 snowstorm had significant impacts in Oklahoma. It almost completely shut down the central and northwestern parts of the state because of high snow accumulations on the ground, from 12 to $19 \mathrm{in}$. $(\sim 30-50 \mathrm{~cm})$ as measured by the ruler. Western parts of Oklahoma received 1-4 in. (about $2.5-10 \mathrm{~cm}$ ) of snow on the ground (Bukovčić 2017). The measurements of total SWE obtained from CoCoRaHS (total storm amount) near Washington (Oklahoma), were $12 \mathrm{~mm}$. The Washington Oklahoma Mesonet measurement of total SWE (a few days after the storm, when snow melted) was $\sim 6.3 \mathrm{~mm}$. Because of the time lag between the actual snowfall and the time when melted snow was measured by the Washington Oklahoma Mesonet (nonheated rain gauge), substantial sublimation occurred. We estimate $\sim 40 \%-50 \%$ loss of SWE due to sublimation in this time period. Accounting for this loss, we submit that the adjusted SWE from the Washington Oklahoma Mesonet is between 10.45 and $12.6 \mathrm{~mm}$; therefore, the mean estimate is $\sim 11.5 \mathrm{~mm}$ (in agreement with the National Weather Service storm reports). This value is used for tuning the collocated 2DVD that produces the data that are used for comparison with the radar estimates.

The PPIs of the $Z, K_{\mathrm{DP}}, Z_{\mathrm{DR}}$, and $\rho_{\mathrm{hv}}$ at $1138 \mathrm{UTC}$ are presented in Fig. 6. Precipitation (snow) is widespread across the whole domain, where some enhanced values of $Z(\sim 35 \mathrm{~dB} Z)$ and $K_{\mathrm{DP}}\left(0.12^{\circ}-0.2^{\circ} \mathrm{km}^{-1}\right)$ from south-southeast to east-northeast suggest higher snowfall rates. $Z_{\mathrm{DR}}$ and $K_{\mathrm{DP}}$ are noisy and relatively low, whereas $\rho_{\mathrm{hv}}$ is mostly uniform $(>0.99)$, as expected for aggregated snow. A few sectors with beam blockage are evident in the northeast. The averaging box [black-outlined rectangle $\sim 29 \mathrm{~km}$ south from KOUN (Norman, Oklahoma); Fig. 6a] has a size of approximately $5 \mathrm{~km}$ by $5 \mathrm{~km}$, which translates to $\sim 220$ points used for averaging of polarimetric variables (hence the decrease in the standard deviation of the polarimetric variables estimate by a factor of $220^{1 / 2} \approx 15$ ).

Time series of snowfall-rate estimates from 2DVD, $S\left(K_{\mathrm{DP}}, Z\right), S\left(K_{\mathrm{DP}}, Z_{\mathrm{dr}}\right)$, and $S(Z)$ are presented in Fig. $7 \mathrm{a}$, whereas their respective SWE accumulations are in Fig. 7b. The 2DVD estimates are adjusted to match the amount estimated from the storm total SWE gauge measurements (described at the beginning of the section). The time of the radar estimates, accounting for the altitude difference, is adjusted to 2DVD measurements 

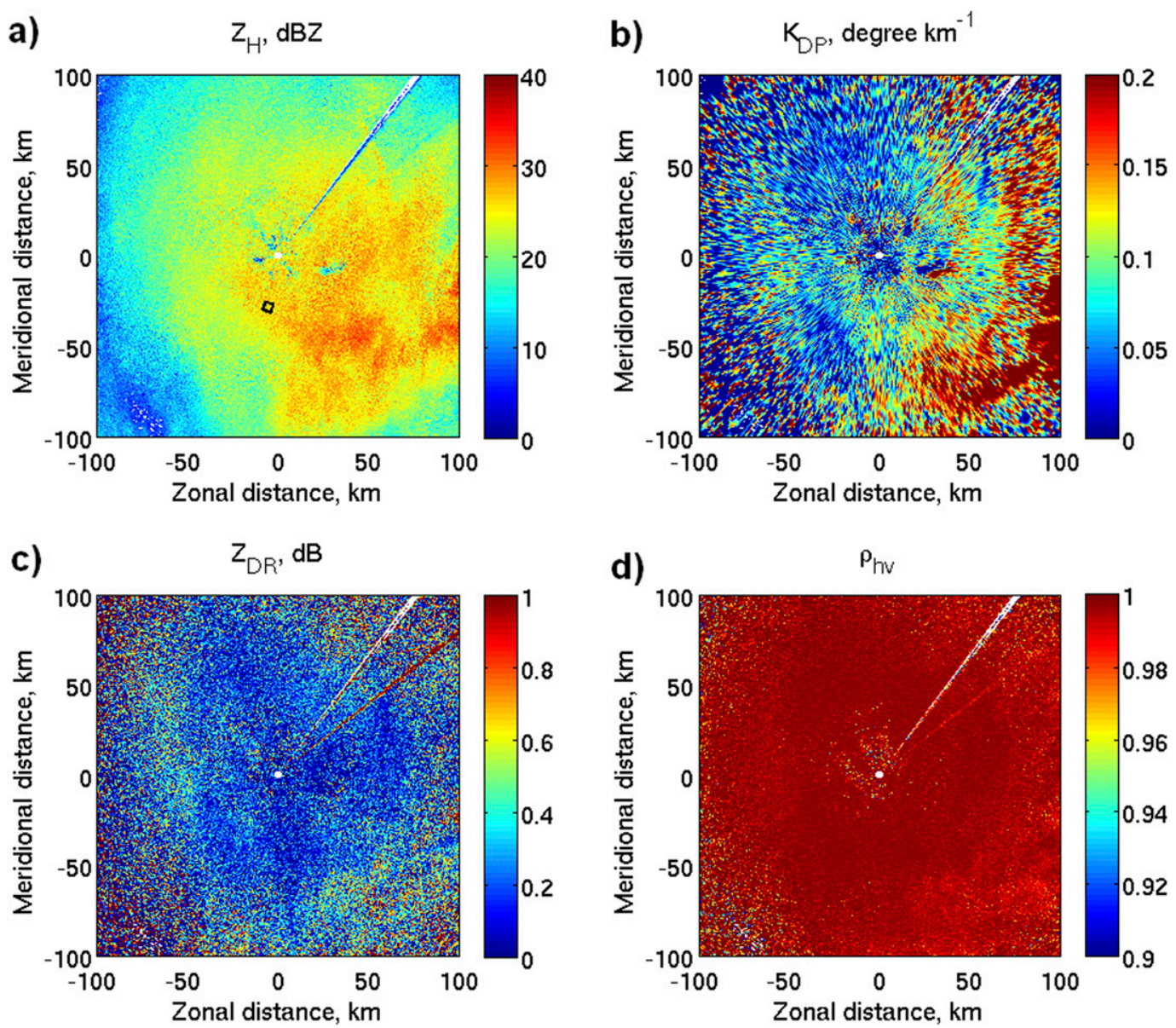

FIG. 6. PPIs of (a) $Z$, (b) $K_{\mathrm{DP}}$, (c) $Z_{\mathrm{DR}}$, and (d) $\rho_{\mathrm{hv}}$, for KOUN $1.45^{\circ}$ radar elevation angle at Norman at 1138 UTC $1 \mathrm{Feb} 2011$. The black-outlined rectangle encompasses the approximately $5^{\circ}$ in azimuth by 20 range points used for averaging, roughly $5 \mathrm{~km}$ by $5 \mathrm{~km}$; the height of the rectangle center is $\sim 0.8 \mathrm{~km}$ AGL, with the 2DVD location ( $\sim 29 \mathrm{~km}$ south of KOUN) directly below.

using $\sim 1 \mathrm{~m} \mathrm{~s}^{-1}$ snow terminal velocity. For more details about the 2DVD measurements, the reader is referred to Bukovčić et al. (2018). The $S\left(K_{\mathrm{DP}}, Z\right)$ rate is in very good agreement with $2 \mathrm{DVD}$ from 0830 UTC until 1400 UTC, but it overestimates the rates for two snowbands from 1415 to 1515 UTC and from 1600 to 1730 UTC (red curve). Within the snowbands, the maximum particle sizes are larger, up to $12 \mathrm{~mm}$, (particle sizes ranging up to $5-6 \mathrm{~mm}$ were observed during nonconvective phases of the snow) but the overall concentration of particles is smaller, especially for small particles $(D<1 \mathrm{~mm}, 2 \mathrm{DVD}$ measurements; not shown). The mean volume diameter $D_{m}$ is up to 9.5 and $7.5 \mathrm{~mm}$ for the later two periods, but it ranges from 1 to $3 \mathrm{~mm}$ earlier. The $S\left(K_{\mathrm{DP}}, Z_{\mathrm{dr}}\right)$ estimate (green curve) is in good agreement with gauges throughout the event, marginally underestimating the rates from 0930 to 1100 UTC and slightly overestimating $S$ to the end of the event. The good agreement is expected because the temperature on the ground ranged from $-8.5^{\circ}$ to $-13^{\circ} \mathrm{C}$, causing DGL to descend closer to the surface. The $S\left(K_{\mathrm{DP}}, Z_{\mathrm{dr}}\right)$ relation is sensitive to $Z_{\mathrm{DR}}$ calibration, especially for small $Z_{\mathrm{DR}}$ values, slightly above zero. For example, the $Z_{\mathrm{DR}}$ bias is estimated (by looking at the periods of aggregated snow using RD-QVP) at $0.35 \mathrm{~dB}$, but it easily could be $0.325 \mathrm{~dB}$ instead. With this value, $Z_{\mathrm{DR}}$ varies from 0.02 to $0.33 \mathrm{~dB}$ from 0830 to $1400 \mathrm{UTC}$, whereas in the later two periods the values are from 0.1 to $1.5 \mathrm{~dB}$. This means that the peak in $S\left(K_{\mathrm{DP}}, Z_{\mathrm{dr}}\right)$ at $\sim 1130$ UTC would be $\sim 1 \mathrm{~mm} \mathrm{~h}^{-1}$ higher. This increases the total accumulation from $S\left(K_{\mathrm{DP}}, Z_{\mathrm{dr}}\right)$ by $\sim 20 \%$. The $S(Z)$ estimates are lower than the 2DVD from 0930 to 1300 UTC when smaller particles with higher concentrations are present; in later two periods the $S(Z)$ rates are in good agreement. This is because $Z$ is proportional to the fourth PSD moment for low-density snow (Bukovčić et al. 2018), hence it is 

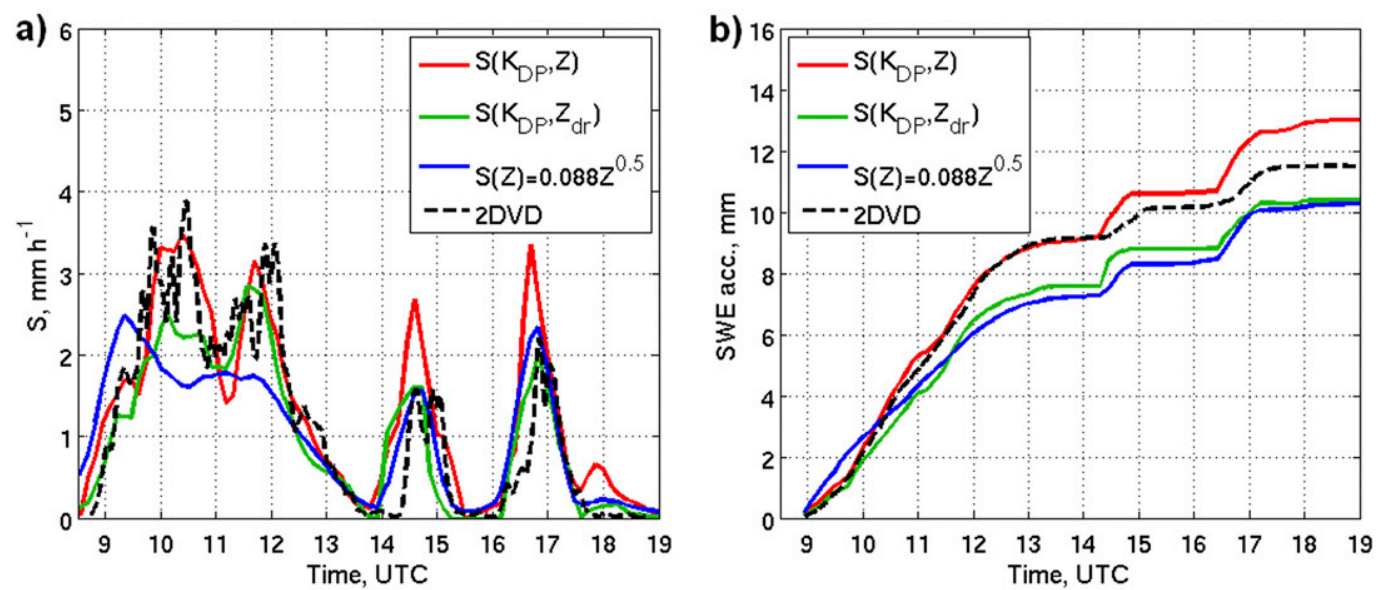

FIG. 7. For 1 Feb 2011, (a) instantaneous snowfall rates $\left(\mathrm{mm} \mathrm{h}^{-1}\right)$ from 2DVD (black dashed curve), $S\left(K_{\mathrm{DP}}, Z\right)$ (red curve), $S\left(K_{\mathrm{DP}}, Z_{\mathrm{dr}}\right)$ (green curve), and $S(Z)$ (blue curve); (b) respective SWE accumulations (mm) from (a). Radar estimates are from $\sim 0.8 \mathrm{~km}$ AGL $\left(1.45^{\circ}\right.$ elevation), obtained directly above the 2DVD location (black rectangle in Fig. $6 \mathrm{a}, \sim 29 \mathrm{~km}$ south of KOUN).

substantially weighted by the largest snowflakes in the size spectrum.

The SWE accumulations from $S\left(K_{\mathrm{DP}}, Z\right)$ are in best agreement overall with $2 \mathrm{DVD}$, especially before the two snowbands passed over the disdrometer. The shape of the $S\left(K_{\mathrm{DP}}, Z_{\mathrm{dr}}\right)$ curve (green) is more consistent with the 2DVD (black dashed curve) than the $S(Z)$ counterpart (blue curve), and its total accumulation is comparable to $\mathrm{S}\left(K_{\mathrm{DP}}, Z\right)$ and slightly better than the one from $S(Z)$.

The CVPs of $Z, K_{\mathrm{DP}}$, and $Z_{\mathrm{DR}}$ presented in Figs. 8a-c show very intriguing storm structure (the gap at the $4 \mathrm{~km}$ in Figs. $8 \mathrm{a}-\mathrm{c}$ is an artifact of the CVP method; linear interpolation is used to fill this gap in Fig. 8d). The cloud tops are much higher (up to $9 \mathrm{~km}$ ) and the storm structure more uniform from 0830 to 1400 UTC than during the later periods when two distinctive cells/bands passed over the site. The enhancements in $K_{\mathrm{DP}}$ from 0830 to 1200 UTC (and also from $\sim 1630$ to 1700 ) are clearly visible in the DGL, extending well below. Perhaps the most interesting signatures are seen in $Z_{\mathrm{DR}}$ aloft. At the time of high cloud tops, $Z_{\mathrm{DR}}$ is very high at the top layer, from $\sim 8.5$ to $9 \mathrm{~km}$, indicating presence of small, low-concentration, pristine crystals $\left(T<-40^{\circ} \mathrm{C}\right)$. Another enhancement in $Z_{\mathrm{DR}}$ is seen within the DGL where dendrites and plates preferably grow. After 1400 UTC, very high values of $Z_{\mathrm{DR}}$ are seen in banded structures extending almost to the ground from lowaltitude clouds. High $Z_{\mathrm{DR}}$ coincide with low $Z$ and $K_{\mathrm{DP}}$ values indicating smaller number of small, horizontally oriented crystals.

SWE accumulations presented in Fig. 8d show almost constant profile obtained from $S\left(K_{\mathrm{DP}}, Z\right)$, and especially from $S\left(K_{\mathrm{DP}}, Z_{\mathrm{dr}}\right)$ below the DGL $(4 \mathrm{~km})$ to the ground. The $S(Z)$ estimate has similar feature but over a much shallower layer, from 1.5 to $0.5 \mathrm{~km}$ AGL. Overall, the profiles constructed from $S\left(K_{\mathrm{DP}}, Z_{\mathrm{dr}}\right)$ are the most consistent with the uniform mass flux hypothesis throughout the layer extending from the DGL to the ground, but the $S\left(K_{\mathrm{DP}}, Z\right)$ is not significantly different.

\section{c. 28 January 2013 case, Grand Mesa, Colorado}

From January until April 2013, a winter precipitation measurement experiment was conducted in the vicinity of Grand Mesa, Colorado, funded by the Water Conservation Board of Colorado. One of the main goals of this experiment was to mitigate the beam blockage of the $\sim 45^{\circ}-50^{\circ}$ azimuthal sector to the east of the KGJX WSR-88D located in Grand Junction, Colorado. The case chosen for presentation had the largest amount of SWE $(22.9 \mathrm{~mm})$ during the experiment, recorded with the heated rain gauge at about $20.9 \mathrm{~km}$ and $97.8^{\circ}$ azimuth from the KGJX radar. The location of the ground instrumentation was in the midst of the beam blockage sector. Because the lowest radar elevations $\left(0.5^{\circ}, 0.9^{\circ}\right.$, and $\left.1.29^{\circ}\right)$ are affected by this blockage, the next available (not affected) elevation $\left(2.4^{\circ}\right)$ is used for verification of $S\left(K_{\mathrm{DP}}, Z\right)$ and $S\left(K_{\mathrm{DP}}\right.$, $Z_{\mathrm{dr}}$ ) relations (see Bukovčic 2017). The altitude of the KGJX radar is $\sim 3045 \mathrm{~m}$ MSL.

The PPIs of $Z, K_{\mathrm{DP}}, Z_{\mathrm{DR}}$, and $\rho_{\mathrm{hv}}$ are presented in Fig. 9. The orographic precipitation is localized in a band about $20-30 \mathrm{~km}$ wide, oriented southwest to northeast. The enhancements in $Z(20-30 \mathrm{~dB} Z)$ are mostly collocated with the enhancements in $K_{\mathrm{DP}}\left(>0.12^{\circ} \mathrm{km}^{-1}\right)$. $Z_{\mathrm{DR}}$ is noisy, with the elevated values $(>0.8 \mathrm{~dB})$ at the 
a)
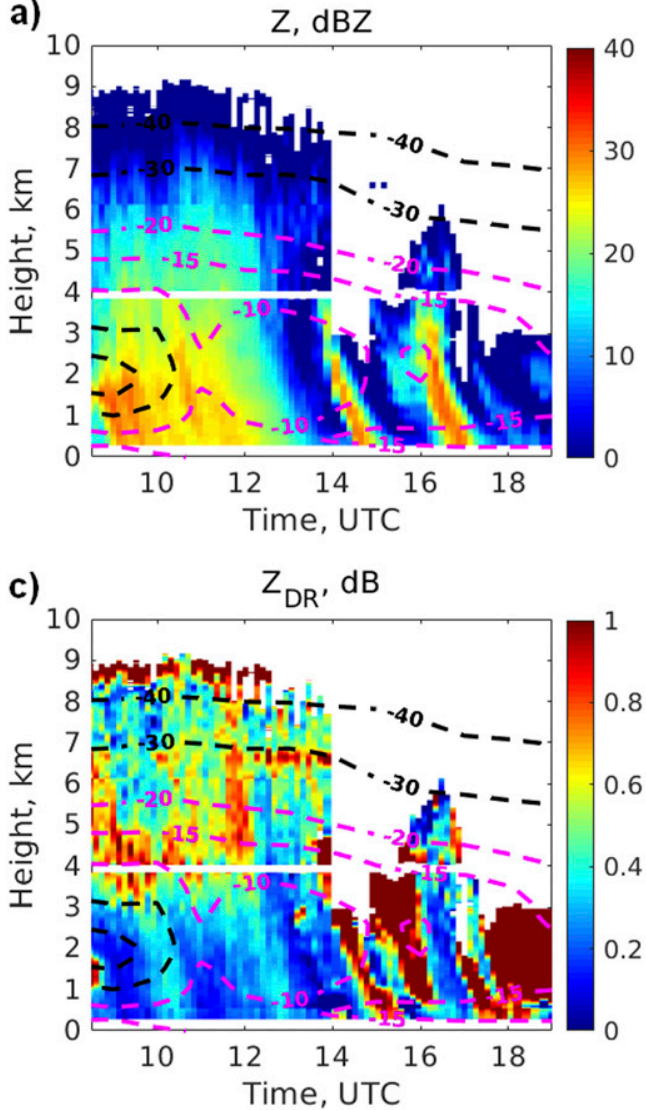

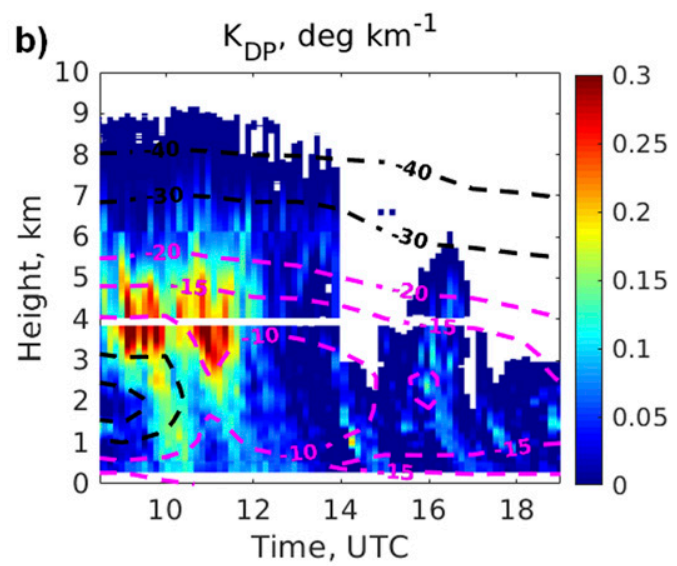

d)

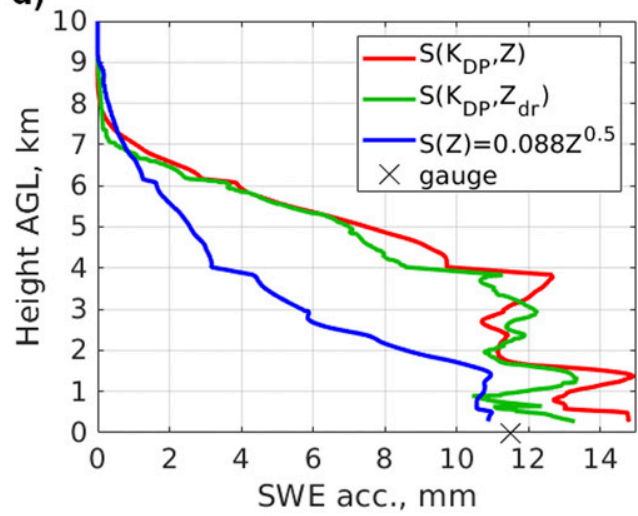

FIG. 8. For KOUN on 1 Feb 2011, CVPs of (a) $Z$, (b) $K_{\mathrm{DP}}$, and (c) $Z_{\mathrm{DR}}$, over the 2DVD site (29 km south of KOUN); the black dashed lines are isotherms, where the layer from $-10^{\circ}$ to $-20^{\circ} \mathrm{C}$ that is highlighted in magenta represents DGL; (d) profiles of SWE accumulations $(\mathrm{mm})$ from gauge (black cross), $S\left(K_{\mathrm{DP}}, Z\right)$ (red curve), $S\left(K_{\mathrm{DP}}, Z_{\mathrm{dr}}\right)$ (green curve), and $S(Z)$ (blue curve).

edges of precipitation, whereas $\rho_{\mathrm{hv}}$ is mostly uniform $(>0.99)$ throughout the domain. Because the precipitation is orographic and localized, the box (black-outlined rectangle $\sim 21 \mathrm{~km}$ east from KGJX; Fig. 9a) used for averaging has a size of approximately $2.5 \mathrm{~km}$ by $2.5 \mathrm{~km}$ (about $\sim 80$ points is used for averaging, which gives the decrease in the standard deviation of the polarimetric variables estimates by a factor of $80^{1 / 2} \approx 9$ ).

The instantaneous snowfall rates $S$ obtained from $2.4^{\circ}$ elevation $(0.85 \mathrm{~km} \mathrm{AGL}, 3900 \mathrm{~m} \mathrm{MSL})$ from $S\left(K_{\mathrm{DP}}\right.$, $Z)\left(\sigma \approx 22^{\circ}, b / a=0.6\right), S\left(K_{\mathrm{DP}}, Z_{\mathrm{dr}}\right), S(Z)$, and heated rain gauge are plotted in Fig. 10a. The radar variables are computed as median values of 80 data points from the box extracted directly above the reference ground measurement location. The $S\left(K_{\mathrm{DP}}, Z\right)$ relation shows the underestimation from 0600 to 1530 UTC and overestimation afterward with respect to the gauge. The $S\left(K_{\mathrm{DP}}, Z_{\mathrm{dr}}\right)$ estimate is similar, but with more fluctuations compared to $S\left(K_{\mathrm{DP}}, Z\right)$, whereas $S(Z)$ is constantly underestimating the snowfall rates, not exceeding $2.1 \mathrm{~mm} \mathrm{~h}^{-1}$. The peaks in $S$ are most appropriately represented by the $S\left(K_{\mathrm{DP}}, Z\right)$.

Snow water equivalent accumulations from the heated gauge, $S\left(K_{\mathrm{DP}}, Z\right), S\left(K_{\mathrm{DP}}, Z_{\mathrm{dr}}\right)$ and standard $S(Z)$ relations as functions of time are presented in Fig. 10b. The $S\left(K_{\mathrm{DP}}, Z\right)$ SWE estimate is the closest $(\sim 16 \mathrm{~mm})$ to the reference measurements $(\sim 22.9 \mathrm{~mm})$. The $S\left(K_{\mathrm{DP}}, Z_{\mathrm{dr}}\right)$ is also close with $\sim 15 \mathrm{~mm}$ of accumulation, whereas $S(Z)$ shows poor performance with $\sim 8 \mathrm{~mm}$ of SWE total amount. Overall, the $S\left(K_{\mathrm{DP}}, Z\right)$ accumulation agrees best with the one from the gauge but $S\left(K_{\mathrm{DP}}, Z_{\mathrm{dr}}\right)$ is very close.

\section{Discussion}

The primary source of uncertainty in the polarimetric estimates of snowfall rate $S$ is the sensitivity of the $S\left(K_{\mathrm{DP}}, Z\right)$ relation to snowflakes' orientation, shape, and density (or degree of riming, which was not explicitly examined in this study). The $S\left(K_{\mathrm{DP}}, Z_{\mathrm{dr}}\right)$ relation is 
a)

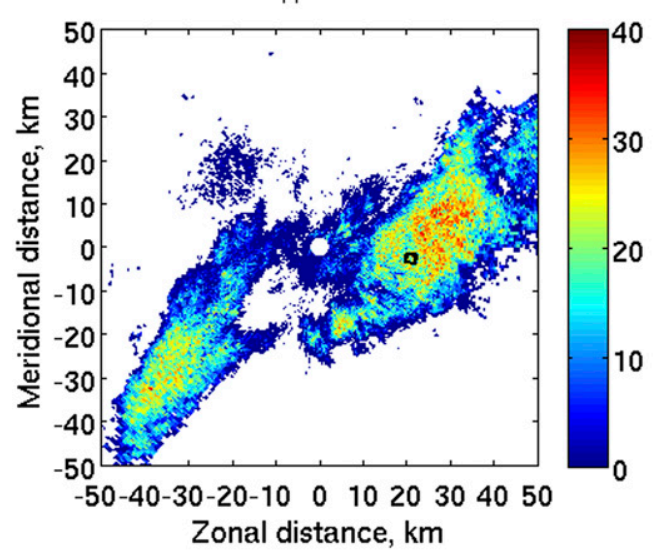

c)

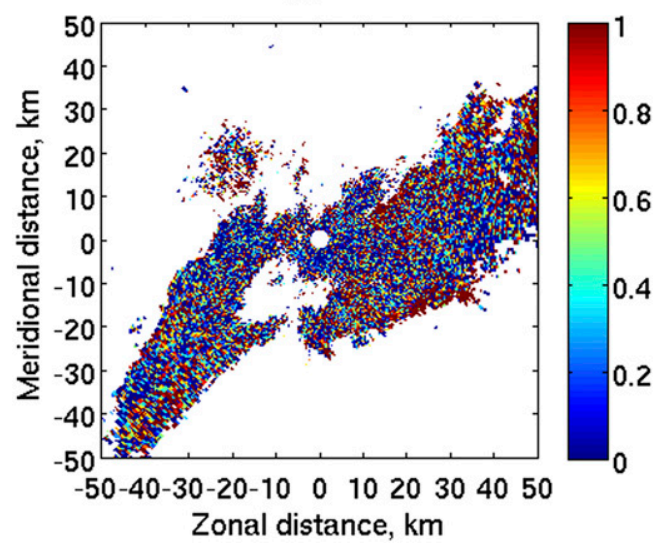

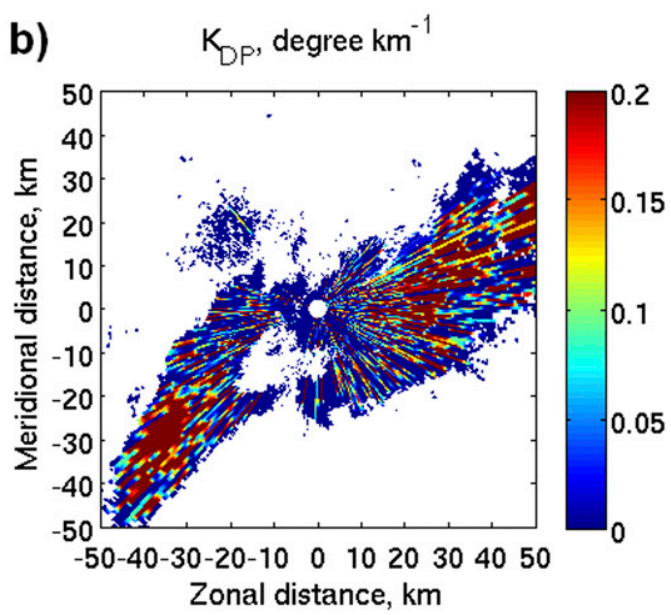

d)

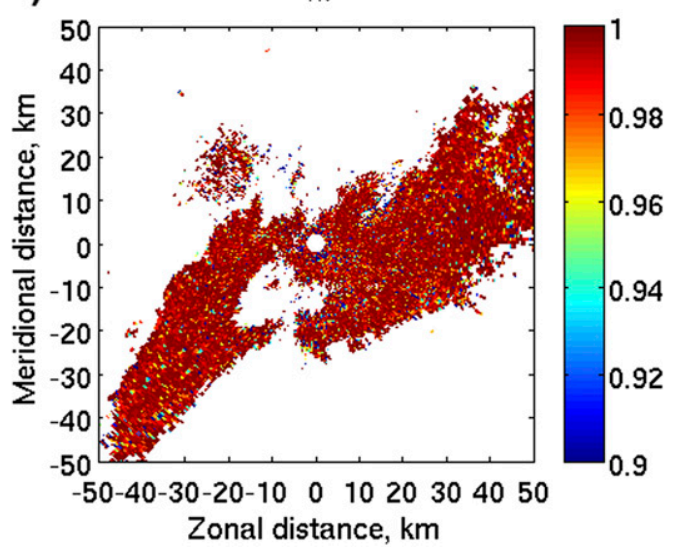

FIG. 9. PPIs of (a) $Z$, (b) $K_{\mathrm{DP}}$, (c) $Z_{\mathrm{DR}}$, and (d) $\rho_{\mathrm{hv}}$ for KGJX $2.4^{\circ}$ radar elevation angle at Grand Junction at 0903 UTC 28 Jan 2013. The black-outlined rectangle represents the $8^{\circ}$ in azimuth by 10 range points used for averaging, roughly $2.5 \mathrm{~km}$ by $2.5 \mathrm{~km}$; the height of the rectangle center is $\sim 0.85 \mathrm{~km}$ AGL, with the gauge location $(\sim 21 \mathrm{~km}$ east of KGJX) directly below.

prone to calibration errors of $Z_{\mathrm{DR}}$ and becomes unstable at low values of $Z_{\mathrm{DR}}$ and $K_{\mathrm{DP}}$. For $K_{\mathrm{DP}}<0.01^{\circ} \mathrm{km}^{-1}$ and $Z_{\mathrm{DR}}<0.3-0.4 \mathrm{~dB}$ (at $\mathrm{S}$ band) the values of $Z_{\mathrm{DR}}$ should be set to $0.3-0.4 \mathrm{~dB}$ or $S\left(K_{\mathrm{DP}}, Z_{\mathrm{dr}}\right)$ should be replaced with the $S\left(K_{\mathrm{DP}}, Z\right)$ relation. The $S\left(K_{\mathrm{DP}}, Z\right)$ is more stable than the $S\left(K_{\mathrm{DP}}, Z_{\mathrm{dr}}\right)$ relation because a product of $K_{\mathrm{DP}}$ and $Z$ rather than the ratio of $K_{\mathrm{DP}}$ and $\left(1-Z_{\mathrm{dr}}^{-1}\right)$ is utilized. The assumed exponential SSD used for the $S\left(K_{\mathrm{DP}}, Z_{\mathrm{dr}}\right)$ derivation can deviate from the actual one due to the SSD natural variability, adding another possible source of error. Snow gauge measurements at the surface, in situ aircraft probes, and polarimetric radar observations can be used to evaluate these uncertainties. Using polarimetric radar data, the "adjustments" of proposed polarimetric relations, and more specifically their multipliers, could be obtained experimentally. Clearly, further study of the subject is in order.
Analysis of the $K_{\mathrm{DP}}$ measurements in heavily aggregated dry snow (at $\mathrm{S}$ band) indicates that $K_{\mathrm{DP}}$ is usually noisy and low-close to zero-and hence, substantial spatial averaging may be required for its reliable estimation (Ryzhkov et al. 1998, 2018). This requirement can be somewhat relaxed at $\mathrm{C}$ and $\mathrm{X}$ bands because of the $K_{\mathrm{DP}}$ 's inverse proportionality to the wavelength. It can be shown that the Rayleigh approximation for computation of $Z$ and $Z_{\mathrm{DR}}$ holds to about 10-12-mm sizes at $X$ band and $16-20 \mathrm{~mm}$ at $\mathrm{C}$ band in low-density snow. In all three frequency bands, the product $K_{\mathrm{DP}} \lambda$ is constant and $K_{\mathrm{DP}}$ is proportional to the fistt moment of size distribution of dry snowflakes. Nonetheless, according to the reference ground measurements and the type of snow, additional tuning may be needed for the $\mathrm{X}$ - and C-band relations.

The sources of discrepancies between the standard and polarimetric radar snowfall relations are also important 

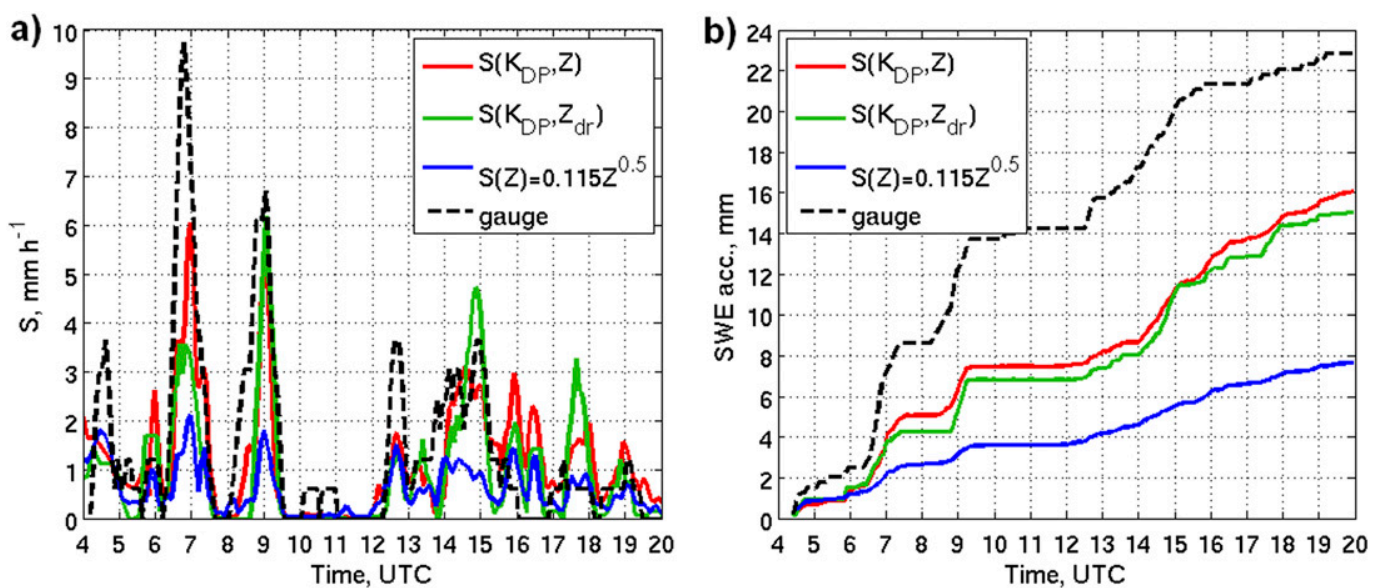

FIG. 10. For 28 Jan 2013 at Grand Mesa, (a) instantaneous snowfall rates $\left(\mathrm{mm} \mathrm{h}^{-1}\right)$ from heated rain gauge (black dashed curve), $S\left(K_{\mathrm{DP}}, Z\right)$ (red curve), $S\left(K_{\mathrm{DP}}, Z_{\mathrm{dr}}\right)$ (green curve), and $S(Z)$ (blue curve); (b) respective $S W E$ accumulations $(\mathrm{mm})$ from (a). Radar estimates are from $\sim 0.85 \mathrm{~km}$ AGL (2.4 elevation), obtained directly above the gauge location (black rectangle in Fig. 9a, $\sim 21 \mathrm{~km}$ east of KGJX).

to identify due to the wide use of the $S(Z)$ relations. A large 2DVD dataset (from dry aggregated snow) indicates that the $S\left(K_{\mathrm{DP}}, Z\right)$ estimate has the lowest standard error, $S\left(K_{\mathrm{DP}}, Z_{\mathrm{dr}}\right)$-low to moderate-whereas the $S(Z)$ is characterized by the highest statistical uncertainty. Also, $Z$ is proportional to the fourth moment of the SSD for low-density (aggregated) snow and is heavily weighted by few largest snowflakes. This is the reason why the $S(Z)$ relation may not adequately capture the natural SSD variability. The addition of $K_{\mathrm{DP}}$, which is proportional to the first SSD moment, reduces the sensitivity of the $S\left(K_{\mathrm{DP}}, Z\right)$ and $S\left(K_{\mathrm{DP}}\right.$, $\left.Z_{\mathrm{dr}}\right)$ estimates to the variability of SSD in low-density snow. The $S(Z)$ may overestimate snowfall rates for very large snowflakes $\left(D_{m}>6 \mathrm{~mm}\right)$ and slightly or moderately underestimate the rates for smaller snowflakes $\left(D_{m}<2 \mathrm{~mm}\right)$.

The use of special processing techniques based on the azimuthal/spatial averaging, for example, quasi-vertical profiles (Ryzhkov et al. 2016; Griffin et al. 2018), rangedefined quasi-vertical profiles (Tobin and Kumjian 2017), and enhanced/column vertical profiles (Bukovčić et al. 2017; Murphy 2018), can diminish the statistical error of $K_{\mathrm{DP}}$ and other polarimetric variable estimates. Hence, the quality of radar snowfall measurements would be significantly improved. However, depending on the storm's homogeneity, the size of the area chosen for averaging can cause the discrepancies in snow estimates. Moreover, $K_{\mathrm{DP}}$ is significantly higher in the dendritic growth layer (the temperature interval between $-10^{\circ}$ and $-20^{\circ} \mathrm{C}$ ) than at warmer temperatures below the DGL (e.g., Kennedy and Rutledge 2011; Bechini et al. 2013). The projections of the DGL $K_{\mathrm{DP}}$ values to the surface (assuming that the snow mass flux is conserved or corrected for the effects of sublimation and riming) is another possibility for the snow measurement improvements.

At the current stage of our research we do not explicitly examine the effects of riming on the polarimetric relations for snow estimates due to the instrumentation and measurements limitations. However, some considerations can be made taking into account different dependencies of $S, Z, K_{\mathrm{DP}}$, and $Z_{\mathrm{DR}}$ on the degree of riming. Our preliminary analysis indicates that light-to-moderate riming may increase the multipliers in the snow-rate estimates by $50 \%$. The process of snow sublimation can reduce the SWE amounts to a large extent if the layer of subsaturated air below the radar beam is deep and dry enough. Horizontal wind is another major factor that affects the snow estimates. For example, starting from $\sim 4 \mathrm{~km}$ AGL the snowflake can travel up to $80-90 \mathrm{~km}$ in the presence of strong winds. The effects of riming, depisitional growth/sublimation, and horizontal wind on polarimetric snow estimation are the subjects for future studies.

\section{Summary}

Verification of polarimetric radar $S\left(K_{\mathrm{DP}}, Z\right)$ and $S\left(K_{\mathrm{DP}}, Z_{\mathrm{dr}}\right)$ relations via reference ground measurements and comparisons with standard $S(Z)$ relations increases confidence in the utilization of these to estimate snowfall. However, polarimetric measurements have issues that need to be dealt with. Specific differential phase $K_{\mathrm{DP}}$ heavily depends on particle density, 
aspect ratio $b / a$, and even more on the width of the canting angle distribution $\sigma$ (Bukovčić 2017). Consequently, the multiplier $\gamma$ or $\gamma_{2}$ in the $S\left(K_{\mathrm{DP}}, Z\right)$ or $\operatorname{IWC}\left(K_{\mathrm{DP}}, Z\right)$ relation, respectively, depends on these quantities while the exponents of $K_{\mathrm{DP}}$ and $Z$ are practically invariant to the changes in snow density, $b / a$, and $\sigma$. Potential $Z_{\mathrm{DR}}$ miscalibration could be a big issue for the $S\left(K_{\mathrm{DP}}, Z_{\mathrm{dr}}\right)$ relation. The fact that $S$ is estimated from the ratio of $K_{\mathrm{DP}}$ and $\left(1-Z_{\mathrm{dr}}^{-1}\right)$ has a positive and negative aspect: the ratio of two small numbers, or a big and a small number could be very large and unstable; but this ratio almost cancels the dependence of $S$ on $b / a$ and $\sigma$ because the numerator and denominator of the ratio are similarly affected by both the aspect ratio and orientations of snowflakes. The current approach relies on some values of these parameters from the existing literature and empirical reasoning, hence future study is needed to solidify these estimates (Bukovčić 2017).

The use of the generalized $S\left(K_{\mathrm{DP}}, Z\right)$ and novel $S\left(K_{\mathrm{DP}}, Z_{\mathrm{dr}}\right)$ relations in three distinct geographical regions (Virginia, Oklahoma, and Colorado) produced encouraging results, seemingly more realistic than the standard $S(Z)$ counterparts, indicating the potentially universal character of these relations. The utility of the novel polarimetric relations for snow measurements hinges on the reliable estimates of $K_{\mathrm{DP}}$ and $Z_{\mathrm{DR}}$, which are very noisy in aggregated snow, especially close to the ground. Hence more accurate snowfall rates estimates from $S\left(K_{\mathrm{DP}}, Z\right)$ and $S\left(K_{\mathrm{DP}}, Z_{\mathrm{dr}}\right)$ may be obtained in the dendritic growth layer. About $80 \%-90 \%$ of total precipitation is produced in the DGL where the $K_{\mathrm{DP}}$ magnitude is significantly higher than in heavily aggregated snow near the surface or just above the freezing level. Under the assumption that the mass flux is conserved, the projection of the $S\left(K_{\mathrm{DP}}, Z\right)$ and especially $S\left(K_{\mathrm{DP}}, Z_{\mathrm{dr}}\right)$ values from this layer to the ground could produce values in better agreement with the ground measurements (Bukovčić 2017). Also, the $S\left(K_{\mathrm{DP}}, Z_{\mathrm{dr}}\right)$ estimator should work better in lower temperature regions $\left(<-10^{\circ} \mathrm{C}\right)$. The use of localized averaging generally improves the accuracy of $K_{\mathrm{DP}}$ and reliability of polarimetric relations. In addition, polarimetric estimates of instantaneous snowfall rates obtained from PPI data show better agreement with the ground measurements compared to the standard $S(Z)$ relations overall. The sensitivity of polarimetric relations to the temperature, relative humidity, riming, and horizontal wind is not explicitly studied in the present work and is a subject of further investigation.

On the basis of physical principles, Bukovčić et al. (2018) suggested a novel concept of snow measurements by polarimetric radar. This study presents the first
S-band radar observational evaluation and the extension of the proposed method. The results are encouraging to justify continued efforts in improving snowfall estimation with polarimetric weather radars.

Acknowledgments. Special thanks are extended to Pengfei Zhang and John Krause for CVP and RD-QVP radar data processing and Dr. Guifu Zhang for the disdrometer data collection. This work is supported by NOAA/Office of Oceanic and Atmospheric Research under NOAA-University of Oklahoma Cooperative Agreement NA16OAR4320115, U.S. Department of Commerce. Additional funding was provided through NSF Grant 1841246.

\section{APPENDIX}

\section{Details of the Derivations}

\section{a. Derivations of $S$ and IWC relations from $K_{D P}$ and $Z$}

Starting from the expression for snowfall rate

$$
S=0.6 \times 10^{-3} \pi \int_{0}^{D \max } \frac{\rho_{s}(D)}{\rho_{w}} D^{3} V_{t}(D) N(D) d D,
$$

where $S$ is in millimeters per hour, $D$ is the equivolume diameter in millimeters and $D_{\max }$ tends to infinity, $\rho_{s}$ and $\rho_{w}$ are the snow and water densities in grams per centimeter cubed, $N(D)$ is the snow size distribution $\left(\mathrm{m}^{-3} \mathrm{~mm}^{-1}\right)$, and $V_{t}(D)$ is terminal/falling velocity in meters per second, one can show that, in Rayleigh approximation,

$$
S=0.6 \times 10^{-3} \pi \alpha_{1} d_{1} f\left(\rho_{a}\right) N_{0 s} \Lambda_{s}^{-\left(4+\beta_{1}+\delta_{1}\right)} \Gamma\left(4+\beta_{1}+\delta_{1}\right),
$$

where $\Gamma$ is the complete gamma function.

This expression holds for the following assumptions: $N(D)$ is the exponential SSD,

$$
N(D)=N_{0 s} \exp \left(-\Lambda_{s} D\right),
$$

the density of snow is inversely proportional to the particle diameter (Brandes et al. 2007),

$$
\rho_{s}(D)=\alpha_{1} D^{\beta_{1}}
$$

where $\beta_{1}$ is close to -1 , and the terminal velocity of snow is also expressed as a power law

$$
V_{t}(D)=\tau_{1} D^{\delta_{1}}=d_{1} f\left(\rho_{a}\right) D^{\delta_{1}},
$$

where $\tau_{1}$ is a function of an air density or pressure, $f\left(\rho_{a}\right)=\left(p_{0} / p\right)^{0.5}$. Here $p_{0}$ and $p$ are the atmospheric 
pressures (standard atmosphere) at the mean sea level $\left(p_{0}=1013 \mathrm{hPa}\right)$ and from the measurement altitude above the mean sea level $(p)$. The factor $\left(p_{0} / p\right)^{0.5}$ represents terminal velocity correction due to the air density change with the altitude (Brandes et al. 2008).

It can also be shown under similar assumptions (see the appendix in Bukovčić et al. 2018) that

$$
\begin{aligned}
Z & =0.224 \alpha_{1}^{2} N_{0 s} \Lambda_{s}^{-\left(7+2 \beta_{1}\right)} \Gamma\left(7+2 \beta_{1}\right) \quad \text { and } \\
K_{\mathrm{DP}} & =\frac{5.66 \times 10^{-2} \pi F_{o} F_{s}}{\lambda} \alpha_{1}^{2} N_{0 s} \Lambda_{s}^{-\left(4+2 \beta_{1}\right)} \Gamma\left(4+2 \beta_{1}\right) .
\end{aligned}
$$

Here $Z$ is in $\mathrm{mm}^{6} \mathrm{~m}^{-3}, K_{\mathrm{DP}}$ is in degrees per kilometer, and $F_{o}$ is the orientation factor, whereas $F_{s}$ is the shape factor (Ryzhkov et al. 2018; Ryzhkov and Zrnic 2019). To obtain the relation between $S$ and $K_{\mathrm{DP}}-Z$, the following functional form is defined:

$$
S=c_{s} K_{\mathrm{DP}}^{a_{s}} Z^{b_{s}}
$$

From (A2), (A6), and (A7) substituting in (A8), it follows that

$$
N_{0 s} \Lambda_{s}^{-\left(4+\beta_{1}+\delta_{1}\right)} \sim N_{0 s}^{a_{s}+b_{s}} \Lambda_{s}^{-\left(4 a_{s}+2 a_{s} \beta_{1}+7 b_{s}+2 b_{s} \beta_{1}\right)} .
$$

From $N_{0 s}$ and $\Lambda_{s}$ exponents in (A9)

$$
\begin{aligned}
& a_{s}=1-b_{s} \text { and } \\
& b_{s}=\frac{-\beta_{1}+\delta_{1}}{3} .
\end{aligned}
$$

Substituting (A11) in (A10) we obtain

$$
a_{s}=\frac{3+\beta_{1}-\delta_{1}}{3} .
$$

It follows from (A11) and (A12) that

$$
S=c_{S} K_{\mathrm{DP}}^{\left(3+\beta_{1}-\delta_{1}\right) / 3} Z^{\left(-\beta_{1}+\delta_{1}\right) / 3} .
$$

Substituting (A2), (A6), and (A7) in (A13), we obtain an expression for $c_{\mathrm{s}}$,

$$
c_{s}=\frac{10.61 \times 10^{-3} d_{1} \times f\left(\rho_{a}\right) \times \Gamma\left(4+\beta_{1}+\delta_{1}\right)}{\alpha_{1}\left[\frac{F_{o} F_{s}}{\lambda} \times \Gamma\left(4+2 \beta_{1}\right)\right]^{\left(3+\beta_{1}-\delta_{1}\right) / 3}\left[1.26 \times \Gamma\left(7+2 \beta_{1}\right)\right]^{\left(\delta_{1}-\beta_{1}\right) / 3}} .
$$

Similarly, if we start from the formulation of IWC $\left(\mathrm{g} \mathrm{m}^{-3}\right)$,

$$
\mathrm{IWC}=\frac{\pi}{6} \times 10^{-3} \int_{0}^{D \max } \rho_{s}(D) D^{3} N(D) d D,
$$

the integration yields

$$
\mathrm{IWC}=\frac{\pi}{6} 10^{-3} \alpha_{1} N_{0 s} \Lambda_{s}^{-\left(4+\beta_{1}\right)} \Gamma\left(4+\beta_{1}\right) .
$$

To obtain an analytical relation between the IWC and $K_{\mathrm{DP}}-Z$, the functional form

$$
\mathrm{IWC}=c_{i} K_{\mathrm{DP}}^{a_{i}} Z^{b_{i}}
$$

is assumed. Substituting (A16), (A6), and (A7) into (A17), we obtain from $N_{0 s}$ exponents

$$
a_{i}=1-b_{i}
$$

and from $\Lambda_{s}$ exponents

$$
b_{i}=-\beta_{1} / 3 \text { and } a_{i}=\left(3+\beta_{i}\right) / 3 .
$$

These values yield the form

$$
\mathrm{IWC}=c_{i} K_{\mathrm{DP}}^{\left(3+\beta_{1}\right) / 3} Z^{-\beta_{1} / 3} .
$$

Solving (A20) for $c_{i}$ from (A6) and (A7) gives the expression

$$
c_{i}=\frac{2.95 \times 10^{-3} \Gamma\left(4+\beta_{1}\right)}{\alpha_{1}\left[\frac{F_{o} F_{s}}{\lambda} \Gamma\left(4+2 \beta_{1}\right)\right]^{\left(3+\beta_{1}\right) / 3}\left[1.26 \Gamma\left(7+2 \beta_{1}\right)\right]^{-\beta_{1} / 3}} .
$$

\section{b. Derivation of $S\left(K_{D P}, Z_{d r}\right)$}

If we start from (A2) and (A16), their ratio gives

$$
\frac{S}{\mathrm{IWC}}=3.6 d_{1} f\left(\rho_{a}\right) \Lambda_{s}^{-\delta_{1}} \frac{\Gamma\left(4+\beta_{1}+\delta_{1}\right)}{\Gamma\left(4+\beta_{1}\right)} .
$$

For an exponential distribution, $\Lambda_{s}=4 / D_{m}$; hence,

$$
\frac{S}{\mathrm{IWC}}=\frac{3.6}{4^{\delta_{1}}} d_{1} f\left(\rho_{a}\right) D_{m}^{\delta_{1}} \frac{\Gamma\left(4+\beta_{1}+\delta_{1}\right)}{\Gamma\left(4+\beta_{1}\right)} .
$$

It follows from (A23)

$$
S=c_{i i} \times \mathrm{IWC} \times D_{m}^{\delta_{1}},
$$


where

$$
c_{i i}=\frac{3.6}{4^{\delta_{1}}} d_{1} f\left(\rho_{a}\right) \frac{\Gamma\left(4+\beta_{1}+\delta_{1}\right)}{\Gamma\left(4+\beta_{1}\right)} .
$$

Ryzhkov and Zrnic (2019) derived an expression for IWC from $K_{\mathrm{DP}}$ and $Z_{\mathrm{dr}}$ as

$$
\operatorname{IWC}\left(K_{\mathrm{DP}}, Z_{\mathrm{dr}}\right)=3.96 \times 10^{-3} \frac{K_{\mathrm{DP}} \lambda}{1-Z_{\mathrm{dr}}^{-1}} .
$$

Substituting (A26) in (A24), we obtain the final form for $S\left(K_{\mathrm{DP}}, Z_{\mathrm{dr}}\right)$

$$
S=c_{i s} \frac{K_{\mathrm{DP}} \lambda}{1-Z_{\mathrm{dr}}^{-1}} D_{m}^{\delta_{1}}
$$

where $Z_{\mathrm{dr}}$ is differential reflectivity in linear units and $\lambda$ and $D_{m}$ are radar wavelength and mean volume diameter in millimeters, with $c_{i s}$ defined as

$$
c_{i s}=\frac{14.26 \times 10^{-3}}{4^{\delta_{1}}} d_{1} f\left(\rho_{a}\right) \frac{\Gamma\left(4+\beta_{1}+\delta_{1}\right)}{\Gamma\left(4+\beta_{1}\right)} .
$$

The expression for $D_{m}$ (Ryzhkov et al. 2018; Ryzhkov and Zrnic 2019) is

$$
D_{m}=-0.1+2 \eta
$$

and $\eta$ is defined as

$$
\eta=\left(\frac{Z_{\mathrm{dp}}}{K_{\mathrm{DP}} \lambda}\right)^{1 / 2}
$$

where $Z_{\mathrm{dp}}=Z_{h}-Z_{v}$ is reflectivity difference in linear units $\left(\mathrm{mm}^{6} \mathrm{~m}^{-3}\right)$, and $Z_{v}$ is reflectivity at vertical polarization.

\section{REFERENCES}

Atlas, D., S. Y. Matrosov, A. J. Heymsfield, M.-D. Chou, and D. B. Wolff, 1995: Radar and radiation properties of ice clouds. J. Appl. Meteor., 34, 2329-2345, https://doi.org/10.1175/15200450(1995)034<2329:RARPOI >2.0.CO;2.

Aydin, K., and C. Tang, 1995: Estimation of ice water content with 94-GHz millimeter wave radar observables. Preprints, 27th Conf. on Radar Meteorology, Vail, CO, Amer. Meteor. Soc., 550-552.

Bechini, R., L. Baldini, and V. Chandrasekar, 2013: Polarimetric radar observations in the ice region of precipitating clouds at C-band and X-band radar frequencies. J. Appl. Meteor. Climatol., 52, 1147-1169, https://doi.org/10.1175/JAMC-D-12-055.1.

Braham, R. R., 1990: Snow particle size spectra in lake effect snow. J. Appl. Meteor., 29, 200-207, https://doi.org/10.1175/15200450(1990)029<0200:SPSSIL>2.0.CO;2.

Brandes, E. A., K. Ikeda, G. Zhang, M. Schonhuber, and R. M. Rasmussen, 2007: A statistical and physical description of hydrometeor distributions in Colorado snowstorms using a video disdrometer. J. Appl. Meteor. Climatol., 46, 634-650, https://doi.org/10.1175/JAM2489.1.

,$- \ldots$, G. Thompson, and M. Schönhuber, 2008: Aggregate terminal velocity/temperature relations. J. Appl. Meteor. Climatol., 47, 2729-2736, https://doi.org/10.1175/2008JAMC1869.1.

Bukovčić, P., 2017: Polarimetric measurements of ice pellets and aggregated snow. Ph.D. dissertation, University of Oklahoma, 120 pp., https://hdl.handle.net/11244/52406.

—_, D. Zrnić, and G. Zhang, 2017: Winter precipitation liquidice phase transitions revealed with polarimetric radar and 2DVD observations in central Oklahoma. J. Appl. Meteor. Climatol., 56, 1345-1363, https://doi.org/10.1175/JAMC-D16-0239.1.

—, A. Ryzhkov, D. Zrnić, and G. Zhang, 2018: Polarimetric radar relations for quantification of snow based on disdrometer data. J. Appl. Meteor. Climatol., 57, 103-120, https://doi.org/ 10.1175/JAMC-D-17-0090.1.

Capozzi, V., M. Montopoli, A. Bracci, E. Adirosi, L. Baldini, G. Vulpiani, and G. Budillon, 2020: Retrieval of snow precipitation rate from polarimetric X-band radar measurements in southern Italy Apennine mountains. Atmos. Res., 236, 104796, https://doi.org/10.1016/j.atmosres.2019.104796.

Delanoë, J. M. E., A. J. Heymsfield, A. Protat, A. Bansemer, and R. J. Hogan, 2014: Normalized particle size distribution for remote sensing application. J. Geophys. Res. Atmos., 119, 4204-4227, https://doi.org/10.1002/2013JD020700.

Field, P. R., 1999: Aircraft observations of ice crystal evolution in an altostratus cloud. J. Atmos. Sci., 56, 1925-1941, https://doi.org/10.1175/1520-0469(1999)056<1925:AOOICE > 2.0.CO;2.

_- , and A. J. Heymsfield, 2003: Aggregation and scaling of ice crystal size distributions. J. Atmos. Sci., 60, 544-560, https://doi.org/10.1175/1520-0469(2003)060<0544:AASOIC > 2.0.CO;2.

Fujiyoshi, Y., T. Endoh, T. Yamada, K. Tsuboki, Y. Tachibana, and G. Wakahama, 1990: Determination of a $Z-R$ relationship for snowfall using a radar and sensitive snow gauges. J. Appl. Meteor., 29, 147-152, https://doi.org/10.1175/1520-0450(1990) 029<0147:DOARFS $>2.0 . \mathrm{CO} ; 2$.

Griffin, E., T. Schuur, and A. Ryzhkov, 2018: A polarimetric analysis of ice microphysical processes in snow, using quasivertical profiles. J. Appl. Meteor. Climatol., 57, 31-50, https:// doi.org/10.1175/JAMC-D-17-0033.1.

Gunn, K. L. S., and J. S. Marshall, 1958: The distribution with size of aggregate snowflakes. J. Meteor., 15, 452-461, https://doi.org/ 10.1175/1520-0469(1958)015<0452:TDWSOA>2.0.CO;2.

Hendry, A., Y. Antar, and G. McCormick, 1987: On the relationship between the degree of preferred orientation in precipitation and dual-polarization radar echo characteristics. Radio Sci., 22, 37-50, https://doi.org/10.1029/RS022i001p00037.

Heymsfield, A., 1977: Precipitation development in stratiform ice clouds: A microphysical and dynamical study. J. Atmos. Sci., 34, 367-381, https://doi.org/10.1175/1520-0469(1977) 034<0367:PDISIC >2.0.CO;2.

_ Z Z. Wang, and S. Matrosov, 2005: Improved radar ice water content retrieval algorithms using coincident microphysical and radar measurements. J. Appl. Meteor., 44, 1391-1412, https://doi.org/10.1175/JAM2282.1.

_- S. Matrosov, and N. Wood, 2016: Toward improving ice water content and snow-rate retrievals from radars. Part I: $\mathrm{X}$ and $\mathrm{W}$ bands, emphasizing CloudSat. J. Appl. Meteor. Climatol., 55, 2063-2090, https://doi.org/10.1175/JAMCD-15-0290.1. 
Hogan, R. J., M. P. Mittermaier, and A. J. Illingworth, 2006: The retrievals of ice water content from radar reflectivity factor and temperature and its use in evaluating a mesoscale model. J. Appl. Meteor. Climatol., 45, 301-317, https://doi.org/ 10.1175/JAM2340.1.

Kennedy, P., and S. Rutledge, 2011: S-band dual-polarization radar observations of winter storms. J. Appl. Meteor. Climatol., 50, 844-858, https://doi.org/10.1175/2010JAMC2558.1.

Korolev, A., and G. Isaac, 2003: Roundness and aspect ratio of particles in ice clouds. J. Atmos. Sci., 60, 1795-1808, https://doi.org/10.1175/1520-0469(2003)060<1795:RAAROP> 2.0.CO;2.

,-- , and J. Hallett, 2000: Ice particle habits in stratiform clouds. Quart. J. Roy. Meteor. Soc., 126, 2873-2902, https:// doi.org/10.1002/qj.49712656913.

Liu, C. L., and A. J. Illingworth, 2000: Toward more accurate retrievals of ice water content from radar measurements of clouds. J. Appl. Meteor., 39, 1130-1146, https://doi.org/10.1175/ 1520-0450(2000)039<1130:TMAROI >2.0.CO;2.

Lo, K. K., and R. E. Passarelli Jr., 1982: Growth of snow in winter storms: An airborne observational study. J. Atmos. Sci., 39, 697-706, https:// doi.org/10.1175/1520-0469(1982)039<0697:TGOSIW>2.0.CO;2.

Lu, Y., K. Aydin, E. Cothiaux, and J. Verlinde, 2015: Retrieving cloud ice water content using millimeter- and centimeterwavelength radar polarimetric observables. J. Appl. Meteor. Climatol., 54, 596-604, https://doi.org/10.1175/JAMC-D-14 0169.1.

Matrosov, S. Y., 2007: Modeling backscatter properties of snowfall at millimeter wavelengths. J. Atmos. Sci., 64, 1727-1736, https://doi.org/10.1175/JAS3904.1.

_ , and A. Heymsfield, 2017: Empirical relations between size parameters of ice hydrometeor populations and radar reflectivity. J. Appl. Meteor. Climatol., 56, 2479-2488, https:// doi.org/10.1175/JAMC-D-17-0076.1.

_ , R. Reinking, and I. Djalalova, 2005: Inferring fall attitudes of pristine dendritic crystals from polarimetric radar data. J. Atmos. Sci., 62, 241-250, https://doi.org/10.1175/JAS-3356.1.

—, C. Campbell, D. Kingsmill, and E. Sukovich, 2009: Assessing snowfall rates from $\mathrm{X}$-band radar reflectivity measurements. J. Atmos. Oceanic Technol., 26, 2324-2339, https://doi.org/ 10.1175/2009JTECHA1238.1.

Melnikov, V., and J. Straka, 2013: Axis ratios and flutter angles of cloud ice particles: Retrievals from radar data. J. Atmos. Oceanic Technol., 30, 1691-1703, https://doi.org/10.1175/ JTECH-D-12-00212.1.

Mitchell, D. L., R. Zhang, and R. Pitter, 1990: Mass-dimensional relationship for ice particles and the influence of riming on snowfall rates. J. Appl. Meteor., 29, 153-163, https://doi.org/ 10.1175/1520-0450(1990)029<0153:MDRFIP > 2.0.CO;2.

Murphy, A., 2018: A microphysical analysis of the stratiform rain region of mesoscale convective systems using polarimetric radar and in situ aircraft measurements. M.S. thesis, School of Meteorology, University of Oklahoma, 124 pp., https:// hdl.handle.net/11244/301727.

Nguyen, C. M., M. Wolde, K. Baibakov, and A. Korolev, 2017: Determination and estimation of high ice water content using
X-band and W-band dual-polarization airborne radar data. 38th Conf. on Radar Meteorology, Chicago, IL, Amer. Meteor. Soc., 89, https://ams.confex.com/ams/38RADAR/webprogram/ Paper321101.html.

$\longrightarrow$, - and A. Korolev, 2019: Determination of ice water content (IWC) in tropical convective clouds from X-band dual-polarization airborne radar. Atmos. Meas. Tech., 12, 5897-5911, https://doi.org/10.5194/amt-12-5897-2019.

Ohtake, T., 1970: Factors affecting the size distribution of raindrops and snowflakes. J. Atmos. Sci., 27, 804-813, https://doi.org/ 10.1175/1520-0469(1970)027<0804:FATSDO > 2.0.CO;2.

Protat, A., and Coauthors, 2016: The measured relationship between ice water content and cloud radar reflectivity in tropical convective clouds. J. Appl. Meteor. Climatol., 55, 1707-1729, https://doi.org/10.1175/JAMC-D-15-0248.1.

Ryzhkov, A. V., and D. S. Zrnic, 2019: Radar Polarimetry for Weather Observations. Springer International Publishing, 486 pp., https://doi.org/10.1007/978-3-030-05093-1.

,-- , and B. A. Gordon, 1998: Polarimetric method for ice water content determination. J. Appl. Meteor., 37, 125-134, https://doi.org/10.1175/1520-0450(1998)037<0125:PMFIWC > 2.0.CO;2.

, P. Zhang, H. Reeves, M. Kumjian, T. Tschallener, S. Troemel, and C. Simmer, 2016: Quasi-vertical profiles-A new way to look at polarimetric radar data. J. Atmos. Oceanic Technol., 33, 551-562, https://doi.org/10.1175/JTECH-D-15-0020.1.

—, P. Bukovčić, A. Murphy, P. Zhang, and G. McFarquhar, 2018: Ice microphysical retrievals using polarimetric radar data. 10th European Conf. on Radar in Meteorology and Hydrology, Ede-Wageningen, Netherlands, KNMI, 40, https://projects.knmi.nl/erad2018/ERAD2018_extended_ abstract_040.pdf.

Sassen, K., 1987: Ice cloud content from radar reflectivity. J. Climate Appl. Meteor., 26, 1050-1053, https://doi.org/10.1175/15200450(1987)026<1050:ICCFRR >2.0.CO;2.

Sekhon, R. S., and R. C. Srivastava, 1970: Snow size spectra and radar reflectivity. J. Atmos. Sci., 27, 299-307, https://doi.org/ 10.1175/1520-0469(1970)027<0299:SSSARR > 2.0.CO;2.

Szyrmer, W., and I. Zawadzki, 2010: Snow studies. Part II: Average relationship between mass of snowflakes and their terminal fall velocity. J. Atmos. Sci., 67, 3319-3335, https://doi.org/ 10.1175/2010JAS3390.1.

Tobin, D. M., and M. R. Kumjian, 2017: Polarimetric radar and surface-based precipitation-type observations of ice pellet to freezing rain transitions. Wea. Forecasting, 32, 2065-2082, https://doi.org/10.1175/WAF-D-17-0054.1.

Vivekanandan, J., V. N. Bringi, M. Hagen, and P. Meischner, 1994: Polarimetric radar studies of atmospheric ice particles. IEEE Trans. Geosci. Remote Sens., 32 (1), 1-10, https://doi.org/ 10.1109/36.285183.

Zhang, G., S. Luchs, A. Ryzhkov, M. Xue, L. Ryzhkova, and Q. Cao, 2011: Winter precipitation microphysics characterized by polarimetric radar and video disdrometer observations in central Oklahoma. J. Appl. Meteor. Climatol., 50, 1558-1570, https://doi.org/10.1175/2011JAMC2343.1. 